\title{
Prognostic signature of early lung adenocarcinoma based on the expression of ribonucleic acid metabolism-related genes
}

\author{
Ruben Pio, PharmD, PhD, ${ }^{\mathrm{a}, \mathrm{b}, \mathrm{c}}$ Jackeline Agorreta, $\mathrm{PhD},{ }^{\mathrm{a}, \mathrm{c}, \mathrm{d}}$ and Luis M. Montuenga, $\mathrm{PhD}{ }^{\mathrm{a}, \mathrm{c}, \mathrm{d}}$
}

\section{ABSTRACT}

Objective: The current staging system for lung cancer is not sufficient to accurately identify those patients with early-stage tumors who would benefit from postsurgery chemotherapy. The objective of this study was to validate a prognostic signature based on the expression of 5 RNA (ribonucleic acid) metabolism-related genes.

Methods: Five lung cancer microarray datasets, 3 from adenocarcinomas and 2 from squamous cell carcinomas, were analyzed. Kaplan-Meier survival curves and Cox proportional hazards models were used to evaluate the relationship between the classifier and recurrence and survival.

Results: Statistically significant differences in relapse-free survival and overall survival were observed when lung adenocarcinoma patients were divided into 3 risk groups. The prognostic information provided by the signature was independent from other demographic and disease variables, including stage. Significant differences in survival were observed between low- and high-risk groups in stage-IB patients: 5-year survival rates ranged from $83 \%$ to $100 \%$ in the low-risk groups, and from $30 \%$ to $71 \%$ in the high-risk groups, depending on the dataset. The RNA metabolism score additionally displayed an association with the benefit of adjuvant chemotherapy $(P<.001)$, suggesting that those patients in the low-risk group are not good candidates for this treatment.

Conclusions: The RNA metabolism signature is a prognostic marker that may be useful for predicting survival and optimizing the benefit of adjuvant chemotherapy in patients with lung adenocarcinoma. (J Thorac Cardiovasc Surg 2015;150:986-92)

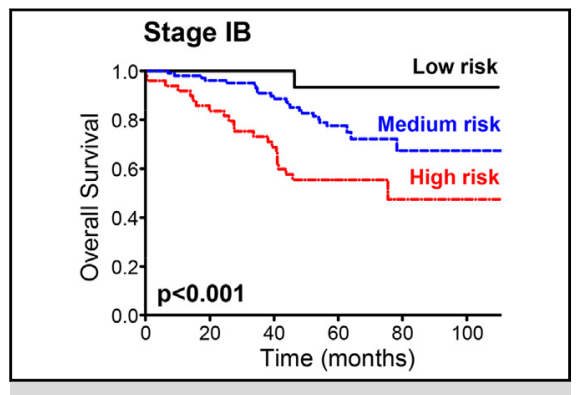

The RNA score accurately predicts overall survival in stage IB lung adenocarcinoma patients.

\section{Central Message}

Expression of 5 RNA metabolism-related genes predicts survival, and benefit of adjuvant therapy in resectable lung adenocarcinomas.

\section{Perspective}

More than half of patients with early-stage lung cancer have a recurrence after surgery, and prognostic factors are needed to select those patients who would benefit from adjuvant therapy. We describe a prognostic signature, based on the expression of RNA metabolism-related genes, that accurately classifies adenocarcinoma patients, independently of stage, and predicts benefit from adjuvant chemotherapy.

See Editorial Commentary page 993. f Supplemental material is available online.

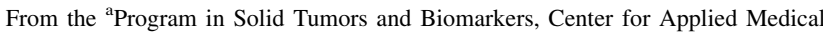
Research (CIMA); ${ }^{b}$ Department of Biochemistry and Genetics, School of Science, University of Navarra; 'Navarra's Health Research Institute (IDISNA); and ${ }^{\mathrm{d} D e p a r t m e n t}$ of Histology and Pathology, School of Medicine, University of Navarra, Pamplona, Spain.

This work was supported by the Foundation for Applied Medical Research (FIMA), Instituto de Salud Carlos III-Fondo Europeo de Desarrollo Regional (RD12/0036/ 0040, PI1 1/00618, PI13/00806, and PI14/01686), and AECC Scientific Foundation (GCB14-2170).

Received for publication March 17, 2015; revisions received May 18, 2015; accepted for publication June 2, 2015; available ahead of print July 7, 2015

Address for reprints: Ruben Pio, PharmD, PhD, Program in Solid Tumors and Biomarkers, Center for Applied Medical Research (CIMA), Pio XII Avenue 55, 31008 Pamplona, Spain (E-mail: rpio@unav.es).

$0022-5223 / \$ 36.00$

Copyright $(\odot) 2015$ by The American Association for Thoracic Surgery

http://dx.doi.org/10.1016/j.jtcvs.2015.06.001
Lung cancer is the leading cause of cancer mortality, representing $>25 \%$ of all cancer deaths. ${ }^{1}$ Non-small cell lung cancer (NSCLC) accounts for approximately $80 \%$ of all lung cancer cases. Currently, only $15 \%$ to $20 \%$ of NSCLC cancer patients present with localized, potentially curable disease. ${ }^{2}$ These numbers are expected to increase in the near future, owing to the implementation of screening programs based on the results of the National Lung Screening Trial. ${ }^{3}$ Surgical resection is the treatment of choice for early-stage NSCLC, but several studies have demonstrated that adjuvant chemotherapy can improve survival. ${ }^{4-6}$ Based on these studies, adjuvant chemotherapy has become the standard of care for resected stage II, but its use is controversial in stage IB, and is not recommended in stage IA. ${ }^{7,8}$ Nevertheless, data suggest that adjuvant chemotherapy is effective for selected patients with stageI NSCLC. ${ }^{9}$ 


\section{Abbreviations and Acronyms \\ $\mathrm{CI}=$ confidence interval \\ DCC = Director's Challenge Consortium (for the Molecular Classification of Lung Adenocarcinoma) \\ NSCLC $=$ non-small cell lung cancer \\ RNA $=$ ribonucleic acid}

Several studies have reported clinicopathologic and molecular prognostic factors in patients with early-stage NSCLC. ${ }^{10-12}$ In search of RNA (ribonucleic acid) metabolism-related genes with altered expression in lung adenocarcinoma, we previously identified a 5-gene categoric classifier with prognostic potential. ${ }^{13}$ The biological importance of RNA metabolism in lung adenocarcinomas is evidenced by the identification of aberrant RNA transcripts associated with somatic mutations in genes encoding splicing factors. ${ }^{14}$ The main objective of the present study was to validate the prognostic performance of the RNA metabolism signature in independent cohorts of patients with early-stage NSCLC. Our study reveals a substantial capacity of the signature to classify adenocarcinoma patients into various risk groups. In addition, the signature shows an association with the benefit of adjuvant chemotherapy.

\section{METHODS}

\section{Patient Cohorts}

Five independent NSCLC microarray datasets were used to assess the prognostic capacity of the RNA metabolism signature: 3 with expression data from adenocarcinoma patients, and 2 from patients with squamouscell carcinoma. Tumor specimens were collected under approval from the respective institutional review boards. All datasets were retrieved from the Gene Expression Omnibus repository (http://www.ncbi.nlm.nih. gov/geo/), except for the files from the Director's Challenge Consortium for the Molecular Classification of Lung Adenocarcinoma (DCC) (https://array.nci.nih.gov/caarray/home.action).

Characteristics of the datasets used in this study are shown in Table 1. Briefly, the DCC dataset was based on expression data from 302 lung adenocarcinoma patients. ${ }^{15}$ Four institutions formed the DCC: the University of Michigan Cancer Center, Moffitt Cancer Center, Memorial SloanKettering Cancer Center, and Dana-Farber Cancer Institute. None of the patients received preoperative chemotherapy or radiation. We divided the patients in the DCC database into those who did not receive any adjuvant therapy $(\mathrm{n}=213)$, and those who received adjuvant chemotherapy $(n=89)$. The GSE31210 dataset contained data from 204 lung adenocarcinoma patients who did not receive postoperative therapy from the National Cancer Center Hospital in Japan. ${ }^{16}$ The GSE13213 dataset was obtained from 117 lung adenocarcinoma patients who underwent potential curative resection at Aichi Cancer Center in Japan. ${ }^{17}$ None of them received adjuvant chemotherapy.

The GSE17710 dataset contained information on 56 primary tumors surgically extracted at the University of North Carolina from treatment-naive patients with lung squamous cell carcinomas. ${ }^{18}$ The fifth NSCLC dataset (GSE4573) contained expression data of resected lung squamous cell carcinomas collected from 129 patients at the University of Michigan Hospital. ${ }^{19}$ No information was found about the use of adjuvant therapy in these patients.

\section{Description of the RNA Metabolism Signature}

The RNA metabolism signature was derived from a comparison of normal lung tissues with lung adenocarcinomas. ${ }^{13}$ Five genes were selected for the prognostic classifier: ADAR2, MARS, RAE1, SNRPB, and SNRPE. The median expression of each of these genes was used to dichotomize tumors as high or low expressers (the probesets used to assess gene expression are specified in Table E1). MARS, RAE1, SNRPB, or SNRPE are overexpressed in lung adenocarcinomas ${ }^{13}$; therefore, tumors with high expression of these 4 genes received 1 risk point for each elevated gene. In the case of $A D A R 2$, this gene is down-regulated in lung tumors and may function as a tumor suppressor. ${ }^{13}$ Consequently, 1 risk point was assigned to those tumors with low expression of $A D A R 2$. The combined risk score was calculated as the sum of the 5 individual scores (ranging from 0 to 5). Patients were divided into 3 risk groups based on the combined risk score: 0 : low risk; 1 to 3 : medium risk; 4 or 5 : high risk.

\section{Statistical Analysis}

The clinical endpoints of the cohorts are shown in Table 1. Overall survival was estimated by the Kaplan-Meier method, and differences between curves were compared with the log-rank test. Kaplan-Meier estimates of survival, with their $95 \%$ confidence intervals (CIs), are shown in Tables E2-E6. Multivariate analyses were performed using the Cox proportional hazards model. Based on univariate Cox significance levels $(P<.2)$, variables were incorporated into Cox models for multivariate analysis. The assumption of proportional hazard was tested by introducing time-dependent covariates into the models. The interaction between the RNA metabolism signature and adjuvant chemotherapy was additionally evaluated, using the Cox proportional hazards model. All statistical analyses were 2-sided. All tests were performed using STATA/IC 12.1 software (Stata Corporation, College Station, Tex).

\section{RESULTS}

Lung adenocarcinoma patients included in the DCC dataset showed important differences in prognosis when divided into low-, medium-, and high-risk groups based on a 5-gene RNA metabolism signature. ${ }^{13}$ To validate this observation, we used 2 independent microarray datasets of lung adenocarcinoma patients: GSE31210 and GSE13213, based on Affymetrix, Inc and Agilent technologies (both Santa Clara, Calif), respectively. Demographics and clinical characteristics of these cohorts are summarized in Tables E7 and E8.

In the GSE31210 dataset (204 lung adenocarcinoma patients), the RNA metabolism score was associated with risk of recurrence and death (Figure 1, $A$ and $B$ ). Cox regression analyses for relapse-free survival and overall survival are shown in Tables E9 and E10, respectively. The prognostic information provided by the RNA metabolism score was independent of other demographic and disease variables, including stage (Table 2). The 5-year survival rates were 95.8\% (95\% CI: $73.9 \%-99.4 \%$ ) for the low-risk group; $89.6 \%$ (95\% CI: $81.4 \%-94.3 \%)$ for the medium-risk group; and $73.8 \%$ (95\% CI: $60.7 \%-83.2 \%)$ for the highrisk group.

Differences in survival were additionally observed among the 117 lung adenocarcinoma patients from the GSE13213 dataset (Figure 1, $C$; and Table E11). A multivariate analysis showed the prognostic importance of the score 
TABLE 1. Summary of the datasets used in the study

\begin{tabular}{lllccc}
\hline Dataset & Cancer type & \multicolumn{1}{c}{ Array platform } & Number of patients & Median follow-up (mon) & Clinical endpoint \\
\hline DCC & Lung ADC & Affymetrix U133A & $213+89$ & 48 & RFS and OS \\
GSE31210 & Lung ADC & Affymetrix U133 Plus 2.0 & 204 & 58 & RFS and OS \\
GSE13213 & Lung ADC & Agilent G4112F & 117 & 68 & OS \\
GSE17710 & Lung SCC & Agilent 44K Custom & 56 & 22 & RFS and OS \\
GSE4573 & Lung SCC & Affymetrix U133A & 129 & 34 & OS \\
\hline
\end{tabular}

For DCC, number of patients indicates 213 patients without adjuvant therapy, and 89 with adjuvant chemotherapy. Affymetrix and Agilent are based in Santa Clara, Calif. $D C C$, Director's Challenge Consortium (for the Molecular Classification of Lung Adenocarcinoma); $A D C$, adenocarcinoma; RFS, relapse-free survival; $O S$, overall survival; $S C C$, squamous cell carcinoma.

as well (Table 2). The 5-year survival rates were: $90.0 \%$ (95\% CI: $47.3 \%-98.5 \%$ ) for the low-risk group; $72.4 \%$ (95\% CI: $60.8 \%-81.0 \%$ ) for the medium-risk group; and $41.9 \%$ (95\% CI: $24.7 \%-58.3 \%$ ) for the high-risk group. We additionally tested whether the prognostic signature was applicable to patients with lung squamous cell carcinoma. We used data from the GSE17710 (56 patients) and GSE4573 (130 patients) datasets, which used Agilent and Affymetrix, Inc, technologies, respectively. The signature was unable to classify patients with lung squamous cell carcinoma into groups with differing prognoses (Figure E1).

We next evaluated the usefulness of the score within separated early stages in the 3 datasets of adenocarcinoma patients. The RNA metabolism signature maintained its prognostic capacity when patients were divided by stages (Figure 2). Data from the individual datasets are shown in Figures E2-E6. In stage IB, important differences in 5 -year survival rates were observed between low- and high-risk groups: $100 \%$ in the low-risk group, and 54.6\% (95\% CI: $32.1 \%-72.4 \%$ ) in the high-risk group for patients in the DCC dataset; $100 \%$ in the low-risk group, and $71.4 \%$ (95\% CI: $40.6 \%-88.2 \%$ ) in the high-risk group for patients in the GSE31210 dataset; and $83.3 \%$ (95\% CI: $27.3 \%$ $97.5 \%)$ in the low-risk group, and $30.0 \%$ (95\% CI: $7.1 \%-57.8 \%)$ in the high-risk group for patients in the GSE13213 dataset. The negative predictive value of the signature in stage-IB patients was $95 \%$ (only 1 of the 21 patients in the low-risk group relapsed).

The potential association between the prognostic groups derived from the signature, and the benefit of adjuvant chemotherapy was evaluated in the DCC cohort, which contains clinical outcome data from 213 patients with no adjuvant therapy, and 89 patients treated with adjuvant chemotherapy (demographics and clinical characteristics of these patients are summarized in Table E12). The RNA metabolism score displayed interactive effects with adjuvant chemotherapy $(P=.013)$, indicating differential responses to chemotherapy among groups. In particular, differences were found in overall survival between patients treated and untreated (in favor of the untreated group) in the low- and medium-risk groups (Figure E7, $A$ and $B$ ); whereas no differences were found between treatment arms in the high-risk group (Figure E7, $C$ ).
A characteristic of the DCC dataset, likely due to a bias in patient selection, is the poorer outcome of those stage-I patients receiving adjuvant chemotherapy. ${ }^{20}$ This fact would explain the increase we observed in the survival of untreated patients in low- and medium-risk groups, and the absence of effect in the high-risk group. Therefore, to better evaluate the beneficial effect of adjuvant therapy in the various risk groups, we analyzed the association between the prognostic score and adjuvant chemotherapy in stages I and II/III separately $(n=196$ and $n=103$, respectively). The interaction between the RNA metabolism score and adjuvant chemotherapy was retained in both groups $(P=.024$ and $P=.045$, respectively). In stage-I patients, differences in favor of the untreated group were still observed, especially in low- and medium-risk groups (Figure $3, A-C$ ). In contrast, in stage-II/III patients, in the low- and medium-risk groups, no differences in survival between patients treated or untreated were found, whereas in patients in the high-risk group, a clear survival improvement after treatment with chemotherapy was observed (Figure 3,D-F). The 5-year survival rate for stage-II/III patients with a high risk of progression was 9.4\% (95\% CI: $0.7 \%-31.8 \%)$ in the untreated group and increased to $41.7 \%$ (95\% CI: $15.2 \%-66.5 \%)$ in the group treated with adjuvant chemotherapy.

\section{DISCUSSION}

This study extensively validates the prognostic capacity of a signature based on the expression of RNA metabolism-related genes in patients who have early-stage lung adenocarcinoma. The signature is composed of 5 genes: MARS, RAE1, SNRPB, SNRPE, and ADAR2, the first 4 of which are up-regulated in lung adenocarcinomas and seem to be associated with cell proliferation or oncogenic potential; the 5th $(A D A R 2)$ is down-regulated and may function as a tumor suppressor. ${ }^{13}$ In accordance with other markers specifically developed for lung adenocarcinomas, ${ }^{21-23}$ our signature was unable to predict survival in patients with lung squamous cell carcinoma, likely reflecting the fundamental molecular and biological differences among these histologic subtypes.

Many gene-expression prognostic signatures have been suggested to predict recurrence or survival in surgically 


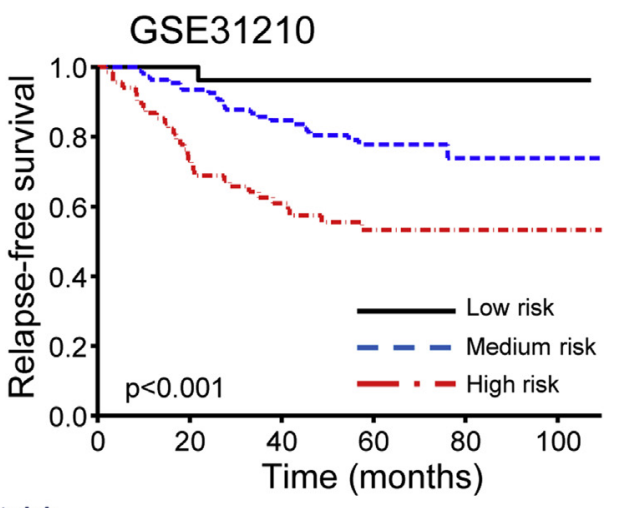

No. at risk

$\begin{array}{rcccccc}\text { Low risk } & 26 & 26 & 23 & 13 & 5 & 1 \\ \text { Medium risk } & 110 & 100 & 80 & 56 & 16 & 5 \\ \text { High risk } & 68 & 49 & 36 & 22 & 7 & 4\end{array}$

A

GSE31210

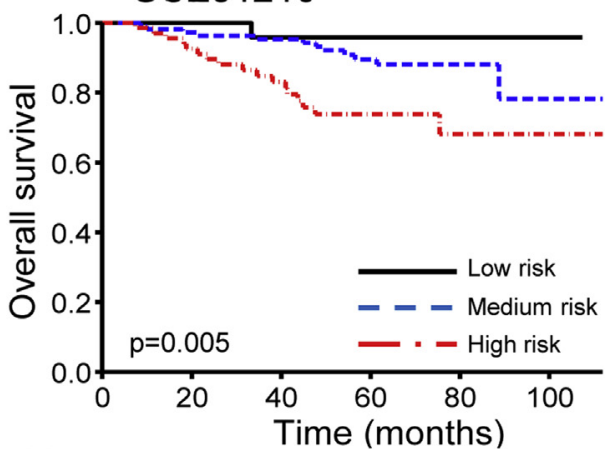

No. at risk

$\begin{array}{lllllll}\text { Low risk } & 26 & 26 & 23 & 13 & 5 & 1\end{array}$

$\begin{array}{lllllll}\text { Medium risk } & 110 & 107 & 92 & 64 & 19 & 5\end{array}$

$\begin{array}{lllllll}\text { High risk } & 68 & 62 & 47 & 28 & 11 & 5\end{array}$

B

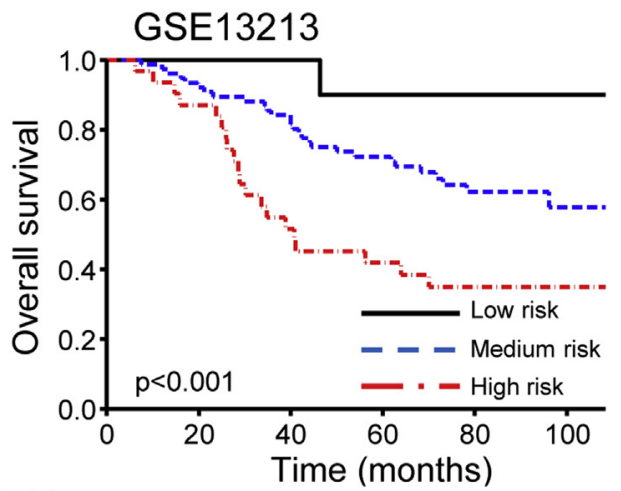

\section{No. at risk}

$\begin{array}{lllllll}\text { Low risk } & 10 & 10 & 10 & 9 & 5 & 2\end{array}$

$\begin{array}{lllllll}\text { Medium risk } & 76 & 70 & 64 & 55 & 28 & 9\end{array}$

$\begin{array}{lllllll}\text { High risk } & 31 & 27 & 16 & 12 & 5 & 2\end{array}$

\section{C}

FIGURE 1. Evaluation of the prognostic capacity of the RNA metabolism signature in lung adenocarcinoma patients: (A) Relapse-free survival in the GSE31210 dataset; (B) Overall survival in the GSE31210 dataset;
TABLE 2. Multivariate Cox regression analysis in lung adenocarcinoma patients from the GSE31210 and GSE13213 databases

\begin{tabular}{|c|c|c|c|}
\hline Database & $\mathbf{n}$ & Hazard ratio $(95 \%$ CI $)$ & $P$ value \\
\hline \multicolumn{4}{|l|}{ GSE31210 $(n=204)$} \\
\hline \multicolumn{4}{|l|}{ Relapse-free survival } \\
\hline \multicolumn{4}{|l|}{ Age (y) } \\
\hline$\leq 60$ & 99 & 1 & .027 \\
\hline$>60$ & 105 & $1.87(1.07-3.26)$ & \\
\hline \multicolumn{4}{|l|}{ Smoking status } \\
\hline Never-smoker & 105 & 1 & .994 \\
\hline Ever-smoker & 99 & $1.00(0.57-1.76)$ & \\
\hline \multicolumn{4}{|l|}{ Stage } \\
\hline I & 162 & 1 & .001 \\
\hline II & 42 & $2.66(1.48-4.79)$ & \\
\hline \multicolumn{4}{|l|}{ EGFR } \\
\hline Wild-type & 185 & 1 & .307 \\
\hline Mutated & 19 & $0.75(0.43-1.30)$ & \\
\hline \multicolumn{4}{|l|}{ Prognostic score } \\
\hline 0 & 26 & 1 & .004 \\
\hline $1-3$ & 110 & $5.53(0.74-41.12)$ & \\
\hline 4,5 & 68 & $12.01(1.61-89.53)$ & \\
\hline \multicolumn{4}{|l|}{ Overall survival } \\
\hline \multicolumn{4}{|l|}{ Gender } \\
\hline Female & 109 & 1 & .843 \\
\hline Male & 95 & $1.10(0.41-3.06)$ & \\
\hline \multicolumn{4}{|l|}{ Smoking status } \\
\hline Never-smoker & 105 & 1 & .684 \\
\hline Ever-smoker & 99 & $1.24(0.43-3.57)$ & \\
\hline \multicolumn{4}{|l|}{ Stage } \\
\hline I & 162 & 1 & .005 \\
\hline II & 42 & $2.98(1.40-6.35)$ & \\
\hline \multicolumn{4}{|l|}{ EGFR } \\
\hline Wild-type & 185 & 1 & .257 \\
\hline Mutated & 19 & $0.65(0.30-1.38)$ & \\
\hline \multicolumn{4}{|l|}{ Prognostic score } \\
\hline 0 & 26 & 1 & .132 \\
\hline $1-3$ & 110 & $2.38(0.31-18.44)$ & \\
\hline 4,5 & 68 & $4.61(0.59-35.81)$ & \\
\hline \multicolumn{4}{|l|}{ GSE13213 $(\mathrm{n}=117)$} \\
\hline \multicolumn{4}{|l|}{ Overall survival } \\
\hline \multicolumn{4}{|l|}{ Stage } \\
\hline I & 79 & 1 & .003 \\
\hline II/III & 38 & $2.38(1.35-4.21)$ & \\
\hline \multicolumn{4}{|l|}{ Prognostic score } \\
\hline 0 & 10 & 1 & .002 \\
\hline $1-3$ & 76 & $2.93(0.39-21.99)$ & \\
\hline 4,5 & 31 & $7.46(0.98-56.62)$ & \\
\hline
\end{tabular}

(C) Overall survival in the GSE13213 dataset. Patients were divided into low-, medium-, and high-risk groups based on the RNA metabolism score, as indicated in the Methods section. The $P$ value of the log-rank test is shown in each graph. 
Stage I

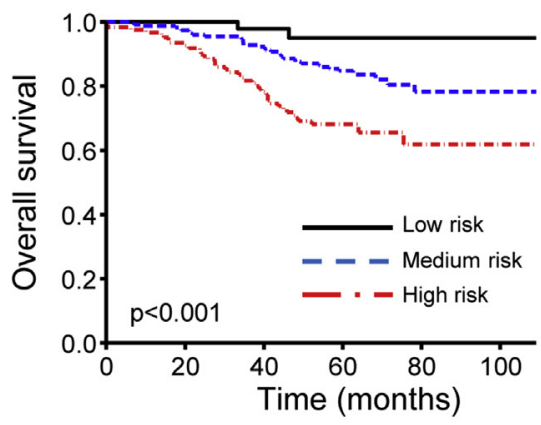

No. at risk

$\begin{array}{rcccccc}\text { Low risk } & 50 & 50 & 42 & 23 & 8 & 2 \\ \text { Medium risk } & 226 & 218 & 184 & 139 & 33 & 12 \\ \text { High risk } & 122 & 112 & 87 & 62 & 13 & 4 \\ \text { A } & & & & & & \end{array}$

Stage IA

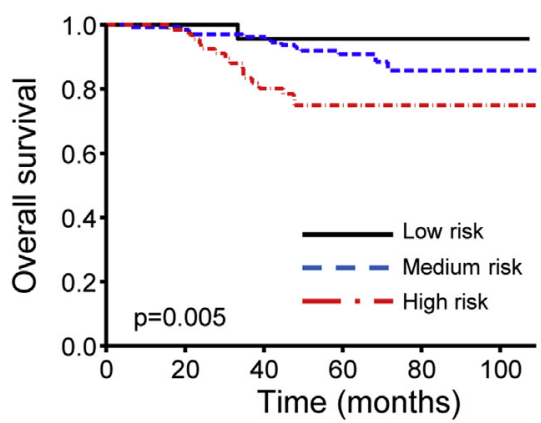

No. at risk

$\begin{array}{rcccccc}\text { Low risk } & 25 & 25 & 22 & 12 & 3 & 1 \\ \text { Medium risk } & 135 & 131 & 115 & 85 & 21 & 6 \\ \text { High risk } & 67 & 66 & 48 & 36 & 8 & 3 \\ \text { C } & & & & & & \end{array}$

Stages II/III

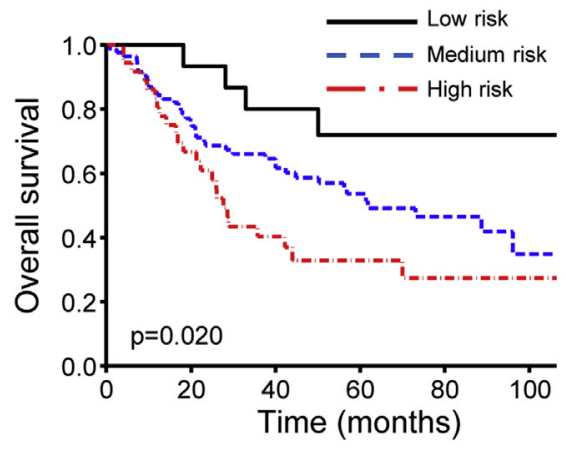

$\begin{array}{rrrcccc}\text { No. at risk } & & & & & & \\ \text { Low risk } & 15 & 14 & 11 & 8 & 1 & 1 \\ \text { Medium risk } & 83 & 63 & 44 & 31 & 14 & 3 \\ \text { High risk } & 36 & 24 & 13 & 8 & 4 & 2\end{array}$

B

\section{Stage IB}

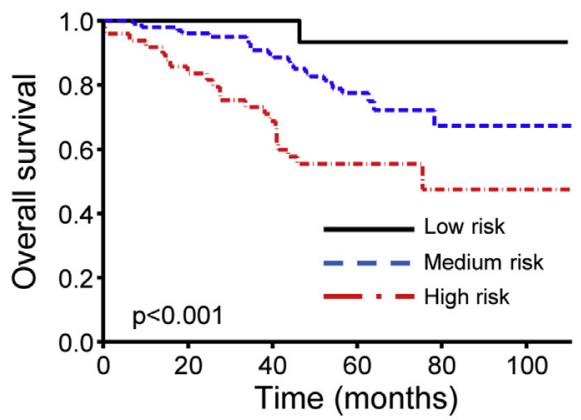

No. at risk

$\begin{array}{rcccccc}\text { Low risk } & 21 & 21 & 18 & 11 & 4 & 1 \\ \text { Medium risk } & 101 & 97 & 79 & 60 & 13 & 5 \\ \text { High risk } & 49 & 40 & 31 & 20 & 5 & 2\end{array}$

D

FIGURE 2. Evaluation of the capacity of the RNA metabolism signature to predict overall survival in lung adenocarcinoma patients, separated by stages. Patients in the low-, medium-, and high-risk groups were combined from the separate analyses performed in the DCC, GSE31210, and GSE13213 datasets ( $\mathrm{n}=534)$. (A) Stage I $(\mathrm{n}=398)$; (B) Stages II and III $(\mathrm{n}=134)$; (C) Stage IA ( $\mathrm{n}=227)$; (D) Stage IB ( $\mathrm{n}=171)$. Patients were divided into low-, medium-, and high-risk groups based on the RNA metabolism score, as indicated in the Methods section. The $P$ value of the log-rank test is shown in each graph.

treated lung cancer patients. ${ }^{24-26}$ However, a major limitation of most signatures is their inconsistent reproducibility in independent datasets. ${ }^{26}$ To date, 2 profiles have been validated rigorously and are available as clinical tests. $^{23,27,28}$ Both of them are based on the expression of cancer-related target genes (11 genes in one of the signatures, and 31 in the other) determined by quantitative polymerase chain reaction on formalin-fixed paraffinembedded tissues. Der and colleagues ${ }^{29}$ have recently validated a 15-gene classifier for patients who have stage I or II NSCLC, which seems to be predictive of improved survival after adjuvant chemotherapy.

Most others signatures have not been validated yet, or are difficult to transfer to the clinical setting because of the large number of genes or the need for sophisticated laboratory techniques or statistical analyses. Our RNA metabolism prognostic signature, based on a straightforward analysis of only 5 genes, has been successfully validated using several independent datasets from various analytic platforms and patients with various ethnicities. Moreover, the signature has shown a clinically meaningful capability to classify patients into groups with different risks of relapse, with a high negative predictive value (ie, high accuracy in identification of patients who are not going to relapse).

Clinically useful prognostic signatures should improve therapeutic decisions, leading to patient benefit. ${ }^{20} \mathrm{~A}$ prognostic test could be considered helpful in cases in which the use of adjuvant chemotherapy is not clearly indicated after consideration of conventional prognostic markers (eg, stage). At present, most patients who are in stage I receive 


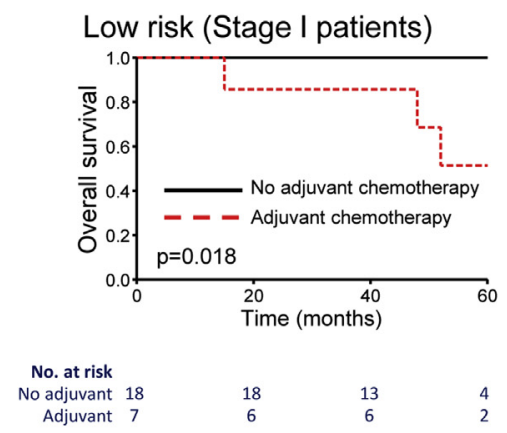

A

Low risk (Stage II/III patients)

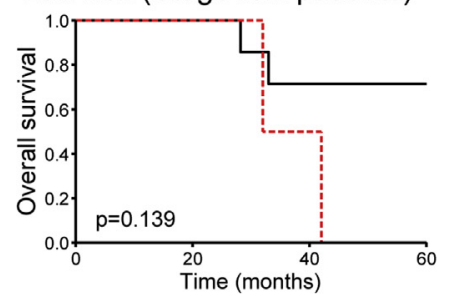

No. at risk

No adjuvant 7

D
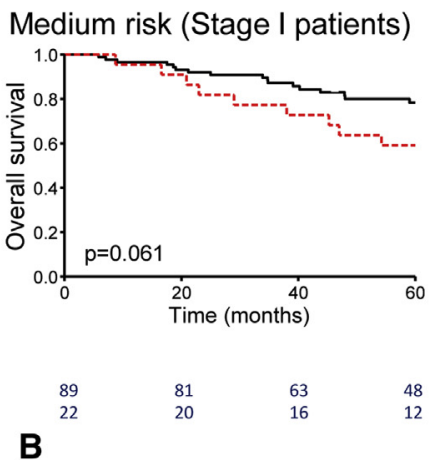

Medium risk (Stage II/III patients)

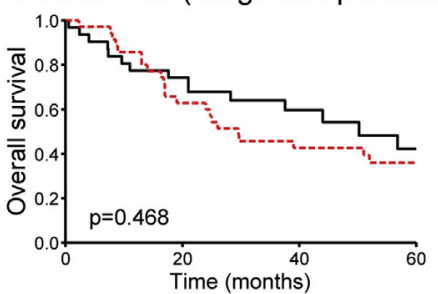

$\begin{array}{cccc}31 & 23 & 13 & 7 \\ 35 & 22 & 14 & 10\end{array}$
High risk (Stage I patients)

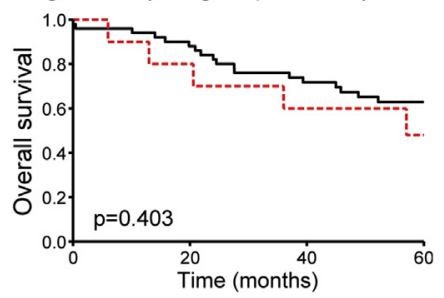

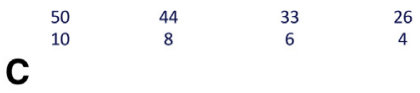

High risk (Stage II/III patients)

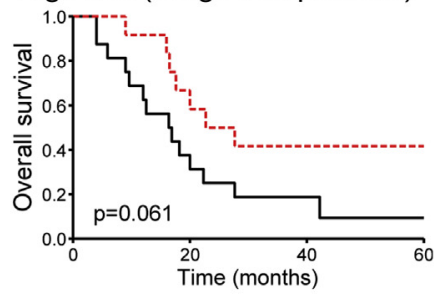

$\begin{array}{rrrr}16 & 6 & 3 & 1 \\ \text { F }^{12} & 8 & 4 & 3\end{array}$

FIGURE 3. Association between the prognostic capacity of the RNA metabolism signature and the benefit of adjuvant chemotherapy in lung adenocarcinoma patients of the DCC dataset. (A) Low-risk group of patients with stage I. (B) Medium-risk group of patients with stage I. (C) High-risk group of patients with stage I. (D) Low-risk group of patients with stage II or III. (E) Medium-risk group of patients with stage II or III. (F) High-risk group of patients with stage II or III. Patients without any events were censored at 60 months. Patients were divided into risk groups based on the RNA metabolism score, as indicated in the Methods section. The $P$ value of the log-rank test is shown in each graph.

only surgical resection, despite the fact that a substantial proportion of them will relapse. Therefore, stage-I patients could benefit the most from a strong prognostic marker.

Our RNA signature was able to identify a subgroup of stage-I patients with a high risk of recurrence. This finding is especially relevant for stage-IB patients, where treatment selection criteria are very poorly defined. In our analysis, only half of the patients in stage IB who were classified as being in the high-risk group survived (compared with $95.5 \%$ of patients in the low-risk group). We tentatively suggest that this type of classifier may be used to help decide whether adjuvant therapy is required in patients who are in stage IB. In fact, we have found an interaction between risk group and benefit of adjuvant chemotherapy. To date, few signatures have demonstrated the ability to predict which patients who have resectable NSCLC will gain a survival benefit with adjuvant chemotherapy. ${ }^{22,30,31}$ In our case, based on the high negative predictive value of the RNA metabolism score, and the differential treatment effects in the various risk groups, we can conclude that those lung adenocarcinoma patients in the low-risk group are not good candidates for adjuvant chemotherapy.

One limitation of our study is the analytic platform on which the validation has been conducted. Although prognostic signatures based on microarray technologies have been successfully applied in the clinic, quantitative polymerase chain reaction is considered the gold standard for messenger RNA expression analysis. This technique requires smaller quantities of tumor tissue and has the advantage of being highly sensitive, reproducible, specific, and easily applicable in the clinical setting. ${ }^{25}$ The results obtained with the RNA metabolism signature justify further validation studies based on polymerase chain reaction technologies. Applying the method to formalin-fixed paraffin-embedded tissues would additionally broaden its potential applications. The added value of the signature to clinical prognostic factors, such as adenocarcinoma subtype, ${ }^{32}$ differentiation, or lymphovascular invasion, ${ }^{11}$ should be evaluated.

Finally, the analysis of the interaction between the risk groups and the benefit of chemotherapy has to be considered preliminary, given that only 1 of the 3 adenocarcinoma datasets used in our study contained patients receiving adjuvant chemotherapy. Additional evaluation of the relationship between the classifier and adjuvant treatment efficacy using appropriate trials is warranted. Moreover, potential associations between the risk score and aspects such as the chemosensitivity of the tumors and the influence of genetic factors merit further evaluation. 
In conclusion, we have validated an RNA metabolism prognostic signature able to classify patients who have early-stage lung adenocarcinoma into risk groups, independently of stage. This signature is based on a straightforward 5-gene score, has shown robust prognostic value in various platforms and cohorts, and has a high negative predictive value in very early stages. The use of this signature may improve the management of lung cancer patients and minimize unnecessary treatment.

\section{Conflict of Interest Statement}

Authors have nothing to disclose with regard to commercial support.

The authors thank Dr Elisabeth Guruceaga for her help in data retrieval.

\section{References}

1. Siegel RL, Miller KD, Jemal A. Cancer statistics, 2015. CA Cancer J Clin. 2015; 65:5-29.

2. Siegel RL, Naishadham D, Jemal A. Cancer statistics, 2012. CA Cancer J Clin. 2012;62:10-29.

3. National Lung Screening Trial Research Team, Aberle DR, Adams AM, Berg CD, Black WC, Clapp JD, Fagerstrom RM, et al. Reduced lung-cancer mortality with low-dose computed tomographic screening. N Engl J Med. 2011;365:395-409.

4. Arriagada R, Bergman B, Dunant A, Le Chevalier T, Pignon JP, Vansteenkiste J, et al. Cisplatin-based adjuvant chemotherapy in patients with completely resected non-small-cell lung cancer. N Engl J Med. 2004;350:351-60.

5. Douillard JY, Rosell R, De Lena M, Carpagnano F, Ramlau R, GonzalesLarriba JL, et al. Adjuvant vinorelbine plus cisplatin versus observation in patients with completely resected stage IB-IIIA non-small-cell lung cancer (adjuvant navelbine international trialist association [ANITA]): A randomised controlled trial. Lancet Oncol. 2006;7:719-27.

6. Pignon JP, Tribodet H, Scagliotti GV, Douillard JY, Shepherd FA, Stephens RJ, et al. Lung adjuvant cisplatin evaluation: a pooled analysis by the LACE collaborative group. J Clin Oncol. 2008;26:3552-9.

7. Strauss GM, Herndon JE II, Maddaus MA, Johnstone DW, Johnson EA, Harpole DH, et al. Adjuvant paclitaxel plus carboplatin compared with observation in stage IB non-small-cell lung cancer: CALGB 9633 with the Cancer and Leukemia Group B, Radiation Therapy Oncology Group, and North Central Cancer Treatment Group Study Groups. J Clin Oncol. 2008;26:5043-51.

8. Horn L, Sandler AB, Putnam JB Jr, Johnson DH. The rationale for adjuvant chemotherapy in stage I non-small cell lung cancer. J Thorac Oncol. 2007;2: 377-83.

9. Tsutani Y, Miyata Y, Kushitani K, Takeshima Y, Yoshimura M, Okada M. Propensity score-matched analysis of adjuvant chemotherapy for stage I non-small cell lung cancer. J Thorac Cardiovasc Surg. 2014;148:1179-85.

10. Zhang Y, Sun Y, Xiang J, Zhang Y, Hu H, Chen H. A clinicopathologic prediction model for postoperative recurrence in stage IA non-small cell lung cancer. $J$ Thorac Cardiovasc Surg. 2014;148:1193-9.

11. Kuo SW, Chen JS, Huang PM, Hsu HH, Lai HS, Lee JM. Prognostic significance of histologic differentiation, carcinoembryonic antigen value, and lymphovascular invasion in stage I non-small cell lung cancer. J Thorac Cardiovasc Surg. 2014; 148:1200-7.e3.

12. Murthy SC, Reznik SI, Ogwudu UC, Farver CF, Arrossi A, Batizy LH, et al. Winning the battle, losing the war: The noncurative "curative" resection for stage I adenocarcinoma of the lung. Ann Thorac Surg. 2010;90:1067-74.

13. Valles I, Pajares MJ, Segura V, Guruceaga E, Gomez-Roman J, Blanco D, et al. Identification of novel deregulated RNA metabolism-related genes in non-small cell lung cancer. PLoS One. 2012;7:e42086.
14. Cancer Genome Atlas Research Network. Comprehensive molecular profiling of lung adenocarcinoma. Nature. 2014;511:543-50.

15. Director's Challenge Consortium for the Molecular Classification of Lung Adenocarcinoma, Shedden K, Taylor JM, Enkemann SA, Tsao MS, Yeatman TJ, Gerald WL, et al. Gene expression-based survival prediction in lung adenocarcinoma: a multi-site, blinded validation study. Nat Med. 2008; $14: 822-7$

16. Okayama H, Kohno T, Ishii Y, Shimada Y, Shiraishi K, Iwakawa R, et al. Identification of genes upregulated in ALK-positive and EGFR/KRAS/ALKnegative lung adenocarcinomas. Cancer Res. 2012;72:100-11.

17. Tomida S, Takeuchi T, Shimada Y, Arima C, Matsuo K, Mitsudomi T, et al. Relapse-related molecular signature in lung adenocarcinomas identifies patients with dismal prognosis. J Clin Oncol. 2009;27:2793-9.

18. Wilkerson MD, Yin X, Hoadley KA, Liu Y, Hayward MC, Cabanski CR, et al. Lung squamous cell carcinoma mRNA expression subtypes are reproducible, clinically important, and correspond to normal cell types. Clin Cancer Res. 2010;16:4864-75.

19. Raponi M, Zhang Y, Yu J, Chen G, Lee G, Taylor JM, et al. Gene expression signatures for predicting prognosis of squamous cell and adenocarcinomas of the lung. Cancer Res. 2006;66:7466-72.

20. Subramanian J, Simon R. Gene expression-based prognostic signatures in lung cancer: ready for clinical use? J Natl Cancer Inst. 2010;102:464-74.

21. Kratz JR, He J, Van Den Eeden SK, Zhu ZH, Gao W, Pham PT, et al. A practical molecular assay to predict survival in resected non-squamous, non-small-cell lung cancer: development and international validation studies. Lancet. 2012; 379:823-32.

22. Tang H, Xiao G, Behrens C, Schiller J, Allen J, Chow CW, et al. A 12-gene set predicts survival benefits from adjuvant chemotherapy in non-small cell lung cancer patients. Clin Cancer Res. 2013;19:1577-86.

23. Wistuba II, Behrens C, Lombardi F, Wagner S, Fujimoto J, Raso MG, et al. Validation of a proliferation-based expression signature as prognostic marker in early stage lung adenocarcinoma. Clin Cancer Res. 2013;19: 6261-71.

24. Zhu CQ, Pintilie M, John T, Strumpf D, Shepherd FA, Der SD, et al. Understanding prognostic gene expression signatures in lung cancer. Clin Lung Cancer. 2009; 10:331-40.

25. Agullo-Ortuno MT, Lopez-Rios F, Paz-Ares L. Lung cancer genomic signatures. J Thorac Oncol. 2010;5:1673-91.

26. Lin J, Beer DG. Molecular predictors of prognosis in lung cancer. Ann Surg Oncol. 2012;19:669-76.

27. Kratz JR, Van den Eeden SK, He J, Jablons DM, Mann MJ. A prognostic assay to identify patients at high risk of mortality despite small, node-negative lung tumors. JAMA. 2012;308:1629-31.

28. Bueno R, Hughes E, Wagner S, Gutin AS, Lanchbury JS, Zheng Y, et al. Validation of a molecular and pathological model for five-year mortality risk in patients with early stage lung adenocarcinoma. J Thorac Oncol. 2015;10: 67-73.

29. Der SD, Sykes J, Pintilie M, Zhu CQ, Strumpf D, Liu N, et al. Validation of a histology-independent prognostic gene signature for early-stage, non-small-cell lung cancer including stage IA patients. J Thorac Oncol. 2014; 9:59-64.

30. Zhu CQ, Ding K, Strumpf D, Weir BA, Meyerson M, Pennell N, et al. Prognostic and predictive gene signature for adjuvant chemotherapy in resected non-small-cell lung cancer. J Clin Oncol. 2010;28:4417-24.

31. Chen DT, Hsu YL, Fulp WJ, Coppola D, Haura EB, Yeatman TJ, et al. Prognostic and predictive value of a malignancy-risk gene signature in early-stage non-small cell lung cancer. J Natl Cancer Inst. 2011;103:1859-70.

32. Tsao MS, Marguet S, Le Teuff G, Lantuejoul S, Shepherd FA, Seymour L, et al. Subtype classification of lung adenocarcinoma predicts benefit from adjuvant chemotherapy in patients undergoing complete resection. J Clin Oncol. 2015 [Epub ahead of print].

Key Words: RNA metabolism, prognosis, adjuvant chemotherapy, lung cancer, adenocarcinoma, squamous cell carcinoma 


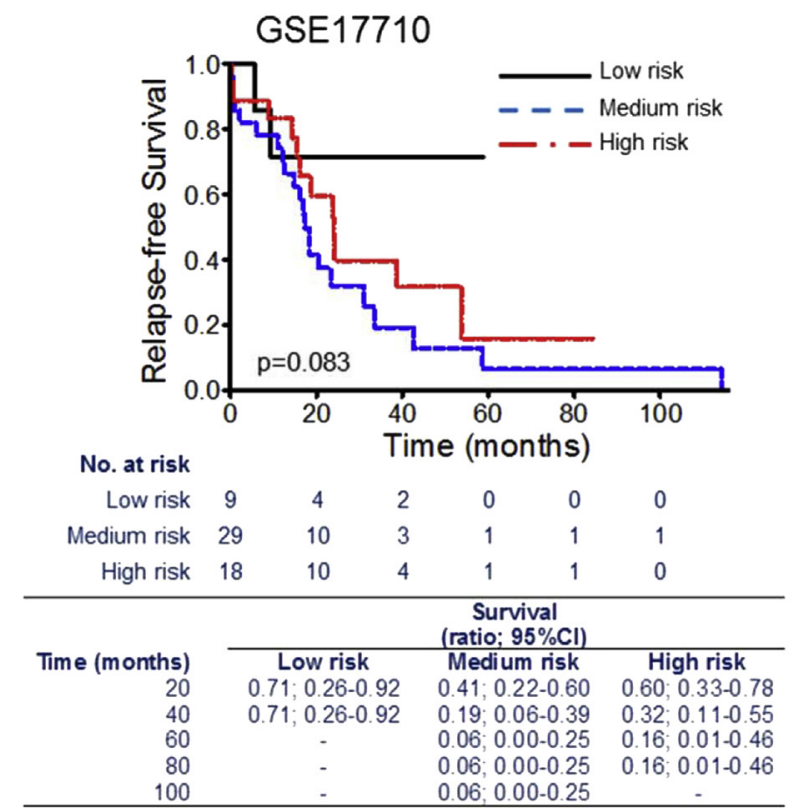

$\mathbf{A}$

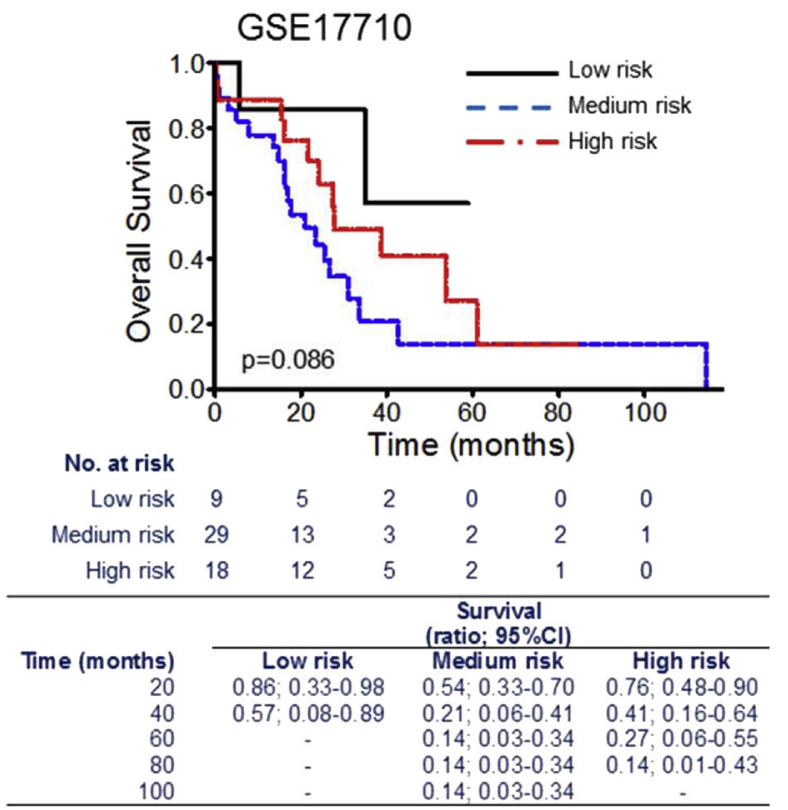

B

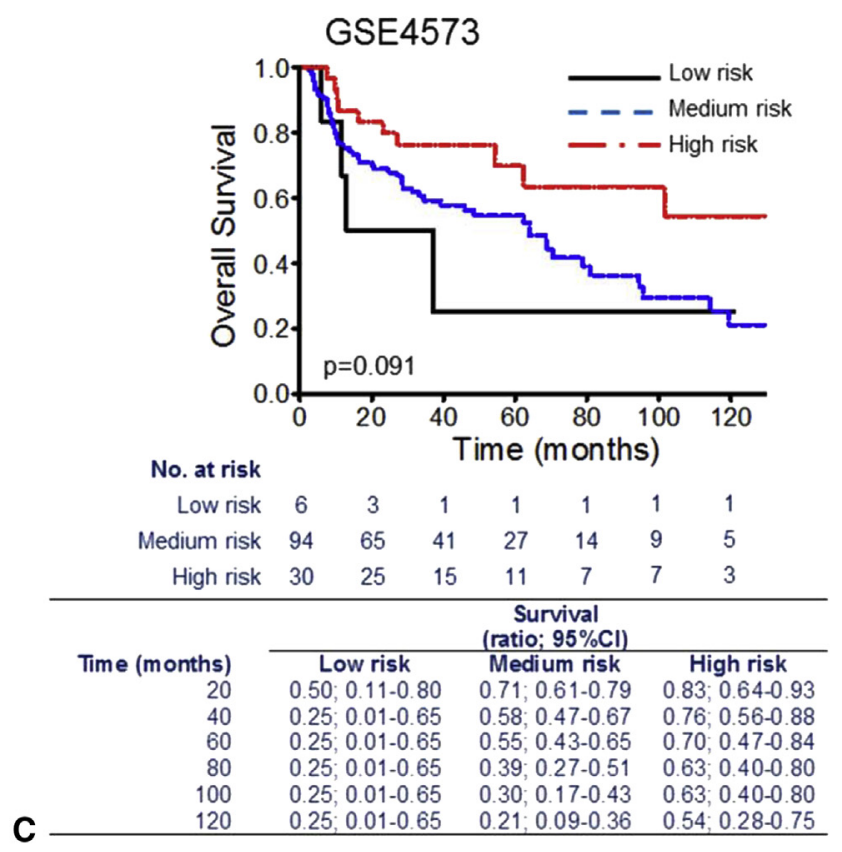

FIGURE E1. Evaluation of the prognostic capacity of the RNA metabolism signature in lung squamous cell carcinoma patients: (A) Relapse-free survival in the GSE17710 dataset; (B) Overall survival in the GSE17710 dataset; (C) Overall survival in the GSE4573 dataset. Patients were divided into low-, medium-, and high-risk groups based on the RNA metabolism score, as indicated in the Methods section. The $P$ value of the log-rank test is shown in each graph. $C I$, Confidence interval. 
Stage I

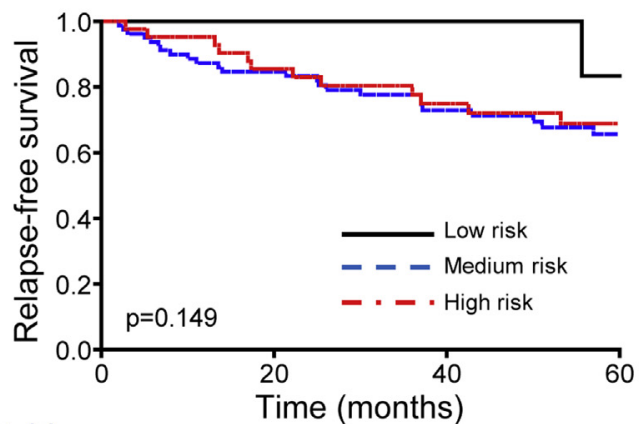

\begin{tabular}{rrrrr}
$\begin{array}{r}\text { No. at risk } \\
\text { Low risk }\end{array}$ & 17 & 17 & 12 & 3 \\
$\begin{array}{r}\text { Medium risk } \\
\text { High risk }\end{array}$ & 41 & 62 & 45 & 32 \\
& & 35 & 26 & 21 \\
\hline & \multicolumn{4}{c}{$\begin{array}{c}\text { Survival } \\
\text { (ratio; 95\%Cl) }\end{array}$} \\
\cline { 2 - 5 } Time (months) & Low risk & Medium risk & High risk \\
20 & 1 & $0.85 ; 0.75-0.91$ & $0.85 ; 0.70-0.93$ \\
40 & 1 & $0.73 ; 0.61-0.82$ & $0.75 ; 0.58-0.86$ \\
60 & $0.83 ; 0.27-0.97$ & $0.66 ; 0.53-0.76$ & $0.69 ; 0.52-0.81$ \\
\hline
\end{tabular}

$\mathbf{A}$

Stage IA

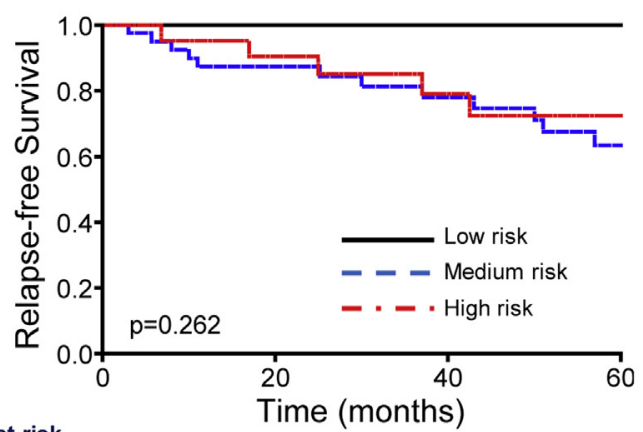

\begin{tabular}{|c|c|c|c|c|}
\hline \multirow{2}{*}{$\begin{array}{r}\text { No. at risk } \\
\text { Low risk }\end{array}$} & \multicolumn{4}{|c|}{ gincise } \\
\hline & 7 & 7 & 6 & 3 \\
\hline Medium risk & 41 & 32 & 24 & 14 \\
\hline \multirow[t]{2}{*}{ High risk } & 21 & 19 & 12 & 11 \\
\hline & & & $\begin{array}{c}\text { Survival } \\
\text { (ratio: } 95 \% \mathrm{Cl} \text { ) }\end{array}$ & \\
\hline \multicolumn{2}{|l|}{ Time (months) } & Low risk & Medium risk & High risk \\
\hline \multicolumn{2}{|c|}{20} & 1 & $0.87 ; 0.72-0.95$ & $0.90 ; 0.67-0.98$ \\
\hline \multicolumn{2}{|c|}{40} & 1 & $0.78 ; 0.61-0.88$ & $0.79 ; 0.53-0.92$ \\
\hline \multicolumn{2}{|c|}{60} & 1 & $0.63 ; 0.44-0.78$ & $0.72 ; 0.45-0.88$ \\
\hline
\end{tabular}

Stages II/III

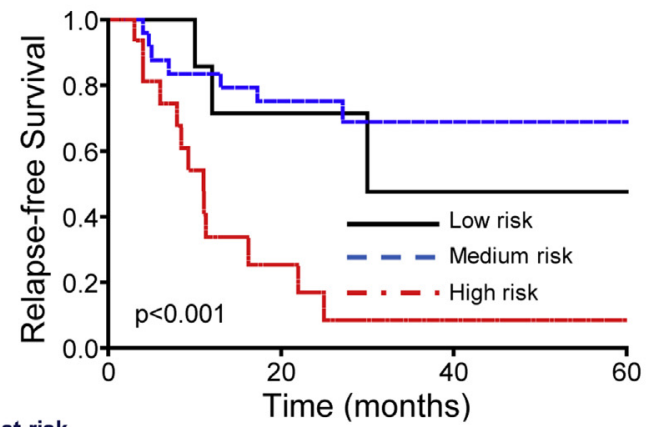

No. at risk

Low risk 7

Medium risk 25

High risk 16

\begin{tabular}{rccc}
\hline & \multicolumn{3}{c}{$\begin{array}{c}\text { Survival } \\
\text { (ratio; 95\%Cl) }\end{array}$} \\
\cline { 2 - 4 } Time (months) & Low risk & Medium risk & High risk \\
20 & $0.71 ; 0.26-0.92$ & $0.75 ; 0.53-0.88$ & $0.25 ; 0.07-0.49$ \\
40 & $0.48 ; 0.08-0.81$ & $0.69 ; 0.45-0.84$ & $0.08-0.01-0.31$ \\
60 & $0.48 ; 0.08-0.81$ & $0.69 ; 0.45-0.84$ & $0.08 ; 0.01-0.31$ \\
\hline
\end{tabular}

B

Stage IB

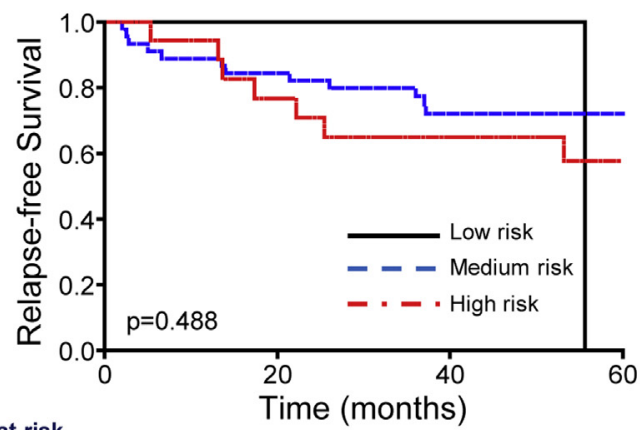

\begin{tabular}{rcccc} 
No. at risk & \multicolumn{4}{c}{0} \\
Low risk & 7 & 6 & 4 & 0 \\
Medium risk & 46 & 37 & 26 & 21 \\
High risk & 20 & 13 & 11 & 7 \\
& & \multicolumn{4}{c}{ Survival } \\
Time (months) & Low risk & Medium risk & High risk \\
\cline { 2 - 4 } Thyyyyy & 1 & $0.84 ; 0.70-0.92$ & $0.77 ; 0.49-0.91$ \\
40 & 1 & $0.72 ; 0.56-0.83$ & $0.65 ; 0.38-0.82$ \\
60 & - & $0.72 ; 0.56-0.83$ & $0.58 ; 031-0.77$ \\
\hline
\end{tabular}

D

FIGURE E2. Evaluation of the capacity of the RNA metabolism signature to predict relapse-free survival in lung adenocarcinoma patients of the DCC dataset, divided by stage: (A) Stage I; (B) Stages II/III; (C) Stage IA; (D) Stage IB. Patients without any events were censored at 60 months. The $P$ value of the log-rank test is shown in each graph. $C I$, Confidence interval. 
Stage I

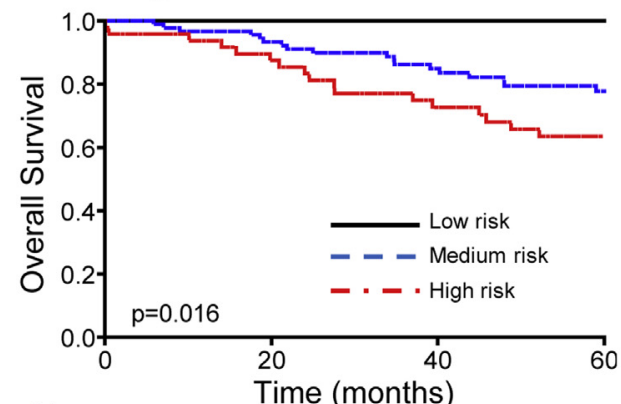

\begin{tabular}{|c|c|c|c|c|}
\hline \multirow{2}{*}{$\begin{array}{r}\text { No. at risk } \\
\text { Low risk }\end{array}$} & \multicolumn{4}{|c|}{ mime (montrs) } \\
\hline & 18 & 18 & 13 & 4 \\
\hline Medium risk & 91 & 83 & 64 & 49 \\
\hline \multirow[t]{2}{*}{ High risk } & 48 & 42 & 32 & 25 \\
\hline & & \multicolumn{3}{|c|}{$\begin{array}{c}\text { Survival } \\
\text { (ratio; } 95 \% \mathrm{Cl} \text { ) }\end{array}$} \\
\hline \multicolumn{2}{|c|}{ Time (months) } & Low risk & Medium risk & High risk \\
\hline & 20 & 1 & $0.93 ; 0.86-0.97$ & $0.87 ; 0.74-0.94$ \\
\hline & 40 & 1 & $0.85 ; 0.75-0.91$ & $0.73 ; 0.57-0.83$ \\
\hline & 50 & 1 & $0.78 ; 0.67-0.85$ & $0.63 ; 0.48-0.76$ \\
\hline
\end{tabular}

A

Stage IA

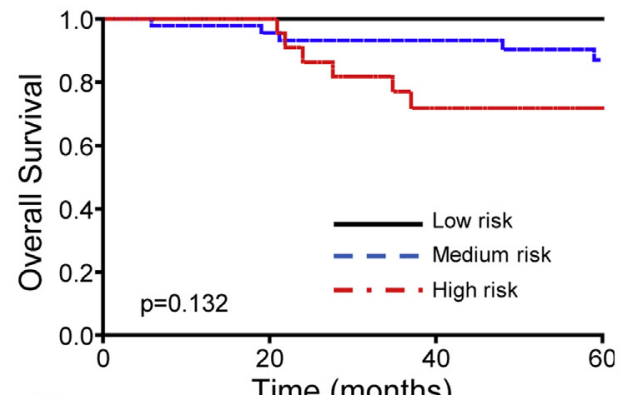

\begin{tabular}{rcccc} 
No. at risk & \multicolumn{4}{c}{ Time (months) } \\
Low risk & 8 & 8 & 7 & 3 \\
Medium risk & 46 & 42 & 34 & 26 \\
High risk & 22 & 22 & 13 & 13 \\
\hline & & \multicolumn{4}{c}{$\begin{array}{c}\text { Survival } \\
\text { (ratio; } 95 \% \text { Cl) } \\
\text { Time (months) }\end{array}$} & Low risk & Medium risk & High risk \\
\cline { 2 - 4 } 20 & 1 & $0.96 ; 0.83-0.99$ & 1 \\
40 & 1 & $0.9 ; 0.81-0.98$ & $0.72 ; 0.48-0.86$ \\
60 & 1 & $0.87 ; 0.71-0.94$ & $0.72 ; 0.48-0.86$ \\
\hline
\end{tabular}

C

FIGURE E3. Evaluation of the capacity of the RNA metabolism signature to predict overall survival in lung adenocarcinoma patients of the DCC dataset, divided by stage: (A) Stage I; (B) Stages II/III; (C) Stage IA; (D) Stage IB. Patients without any events were censored at 60 months. The $P$ value of the log-rank test is shown in each graph. $C I$, Confidence interval.

\section{Stages II/III}

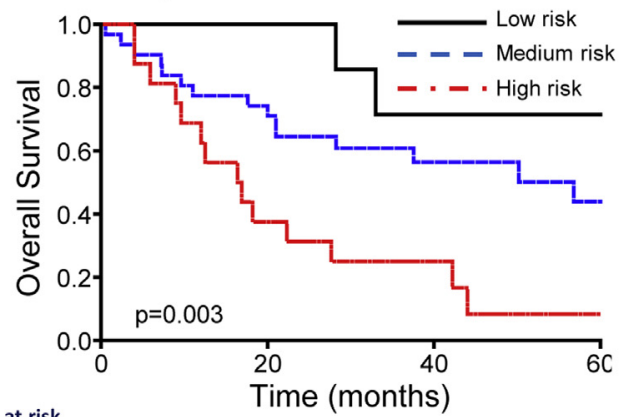

\begin{tabular}{rcccc}
$\begin{array}{r}\text { No. at risk } \\
\text { Low risk }\end{array}$ & 7 & 7 & 4 & 4 \\
$\begin{array}{r}\text { Medium risk } \\
\text { High risk }\end{array}$ & 31 & 23 & 12 & 7 \\
& & 6 & 4 & 1 \\
\hline Time (months) & \multicolumn{4}{c}{$\begin{array}{c}\text { Survival } \\
\text { (ratio; 95\%Cl) }\end{array}$} \\
\cline { 2 - 5 } 20 & Low risk & Medium risk & High risk \\
40 & $0.71 ; 0.26-0.92$ & $0.71 ; 0.52-0.84$ & $0.37 ; 0.15-0.60$ \\
60 & $0.71 ; 0.26-0.92$ & $0.44 ; 0.37-0.72$ & $0.25 ; 0.08-0.0 .47$ \\
0
\end{tabular}

B

\section{Stage IB}

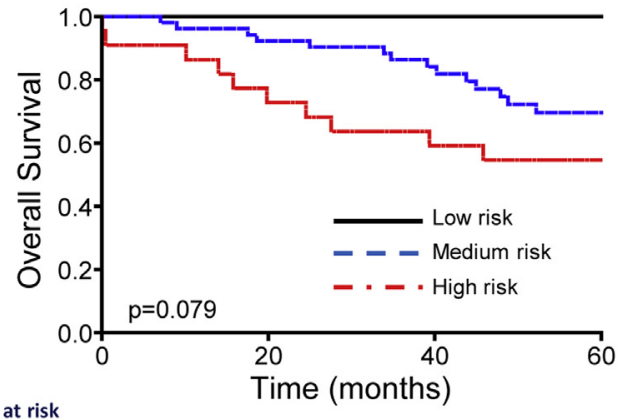

\begin{tabular}{rcccc} 
No. at risk & \multicolumn{4}{c}{1} \\
Low risk & 7 & 7 & 5 & 1 \\
Medium risk & 52 & 48 & 37 & 26 \\
High risk & 22 & 16 & 13 & 9 \\
\hline & & \multicolumn{4}{c}{ Survival } \\
Time (months) & Low risk & Medium risk & High risk \\
\cline { 2 - 4 } 20 & 1 & $0.92 ; 0.81-0.97$ & $0.73 ; 0.49-0.87$ \\
40 & 1 & $0.84 ; 0.71-0.92$ & $0.59 ; 0.36-0.76$ \\
60 & 1 & $0.70 ; 0.54-0.81$ & $0.55 ; 0.32-0.72$ \\
\hline
\end{tabular}

D 


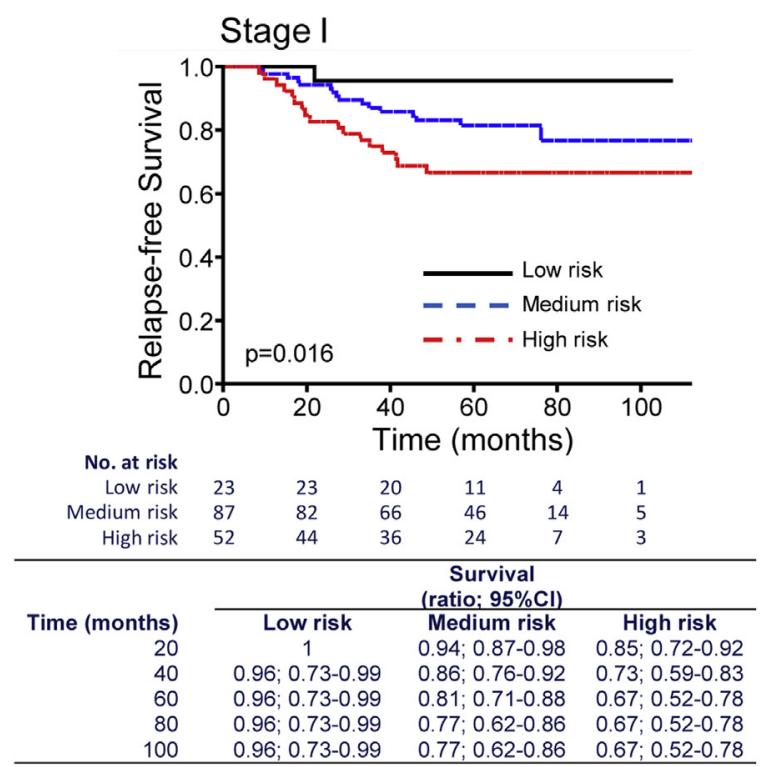

A

Stage IA

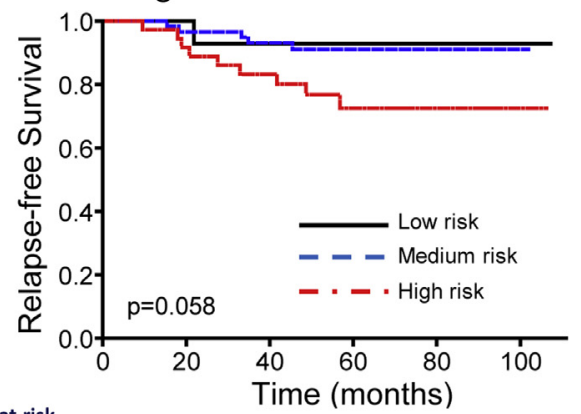

\begin{tabular}{|c|c|c|c|c|c|}
\hline \multirow{2}{*}{$\begin{array}{r}\text { No. at risk } \\
\text { Low risk }\end{array}$} & \multicolumn{5}{|c|}{ Time (months) } \\
\hline & 14 & 14 & 6 & 2 & 1 \\
\hline Medium risk & 59 & 57 & 32 & 9 & 1 \\
\hline \multirow[t]{2}{*}{ High risk } & 36 & 33 & 17 & 5 & 2 \\
\hline & \multicolumn{5}{|c|}{$\begin{array}{c}\text { Survival } \\
\text { (ratio: } 95 \% \mathrm{Cl} \text { ) }\end{array}$} \\
\hline Time (months) & & Low risk & Mediu & & High risk \\
\hline 20 & & 1 & $0.97 ; 0$ & 099 & $0.92 ; 0.76-0.97$ \\
\hline 40 & & $93 ; 0.59-0.99$ & $0.93 ; 0$ & 0.97 & $0.83 ; 0.66-0.92$ \\
\hline 60 & & $93 ; 0.59-0.99$ & $0.91 ; 0$ & 0.96 & $0.73 ; 0.53-0.85$ \\
\hline 80 & & $93 ; 0.59-0.99$ & $0.91 ; 0$ & 0.96 & $0.73 ; 0.53-0.85$ \\
\hline 100 & & $93 ; 0.59-0.99$ & $0.91 ; 0$ & 0.96 & $0.73 ; 0.53-0.85$ \\
\hline
\end{tabular}

C

FIGURE E4. Evaluation of the capacity of the RNA metabolism signature to predict relapse-free survival in lung adenocarcinoma patients of the GSE31210 dataset, divided by stage: (A) Stage I; (B) Stage II; (C) Stage IA; (D) Stage IB. The $P$ value of the log-rank test is shown in each graph. CI, Confidence interval.
Stage II

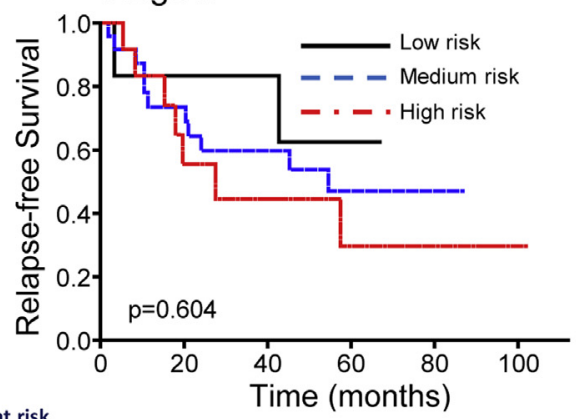

\begin{tabular}{rcccccc} 
No. at risk & \multicolumn{5}{c}{ Time (months) } \\
Low risk & 6 & 4 & 4 & 2 & 0 & 0 \\
Medium risk & 24 & 16 & 10 & 6 & 2 & 0 \\
High risk & 12 & 6 & 3 & 2 & 1 & 1 \\
\hline & \multicolumn{5}{c}{$\begin{array}{c}\text { Survival } \\
\text { (ratio; 95\%CI) }\end{array}$} \\
\cline { 2 - 6 } Time (months) & Low risk & Medium risk & High risk \\
20 & $0.83 ; 0.27-0.97$ & $0.74 ; 0.50-0.87$ & $0.56 ; 0.24-0.79$ \\
40 & $0.83 ; 0.27-0.97$ & $0.60 ; 0.37-0.77$ & $0.44 ; 0.16-0.71$ \\
60 & $0.83 ; 0.27-0.97$ & $0.47 ; 0.24-0.67$ & $0.30 ; 0.06-0.60$ \\
80 & - & $0.47 ; 0.24-0.67$ & $0.30 ; 0.06-0.60$ \\
100 & - & - & $0.30 ; 0.06-0.60$ \\
\hline
\end{tabular}

B

Stage IB

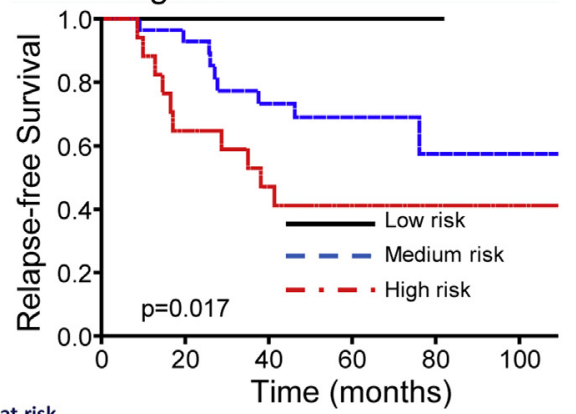

\begin{tabular}{|c|c|c|c|c|c|c|}
\hline \multicolumn{7}{|l|}{ No. at risk } \\
\hline Low risk & 8 & 8 & 7 & 5 & 2 & 0 \\
\hline Medium risk & 28 & 26 & 18 & 15 & 4 & 3 \\
\hline \multirow[t]{2}{*}{ High risk } & 17 & 11 & 8 & 6 & 3 & 2 \\
\hline & & \multicolumn{5}{|c|}{$\begin{array}{c}\text { Survival } \\
\text { (ratio; } 95 \% \mathrm{Cl})\end{array}$} \\
\hline \multicolumn{2}{|l|}{ Time (months) } & \multicolumn{2}{|c|}{ Low risk } & \multicolumn{2}{|c|}{ Medium risk } & High risk \\
\hline \multicolumn{2}{|c|}{20} & \multicolumn{2}{|c|}{1} & \multicolumn{2}{|c|}{$0.93 ; 0.74-0.98$} & $0.65 ; 0.38-0.82$ \\
\hline \multicolumn{2}{|c|}{40} & \multicolumn{2}{|c|}{1} & \multicolumn{2}{|c|}{$0.73 ; 0.52-0.86$} & $0.47 ; 0.23-0.68$ \\
\hline \multicolumn{2}{|c|}{60} & \multicolumn{2}{|c|}{1} & \multicolumn{2}{|c|}{$0.69: 0.47-0.83$} & $0.41 ; 0.19-0.63$ \\
\hline \multicolumn{2}{|c|}{80} & \multicolumn{2}{|c|}{1} & \multicolumn{2}{|c|}{$0.57: 0.29-0.78$} & $0.41 ; 0.19-0.63$ \\
\hline \multicolumn{2}{|c|}{100} & \multicolumn{2}{|c|}{ - } & \multicolumn{2}{|c|}{$057.029-078$} & $0.41 ; 0.19-0.63$ \\
\hline
\end{tabular}

\section{D}




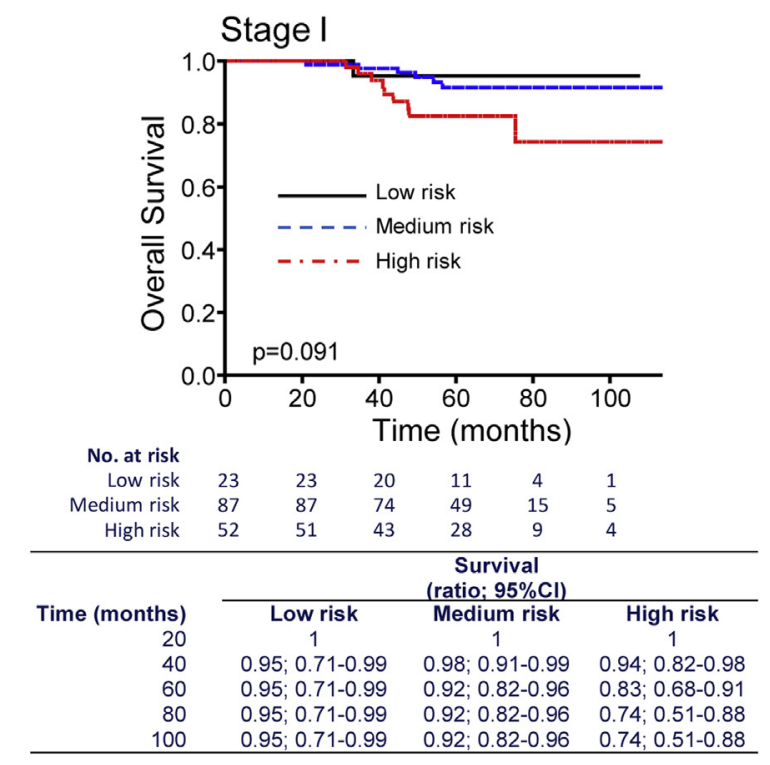

A

Stage IA

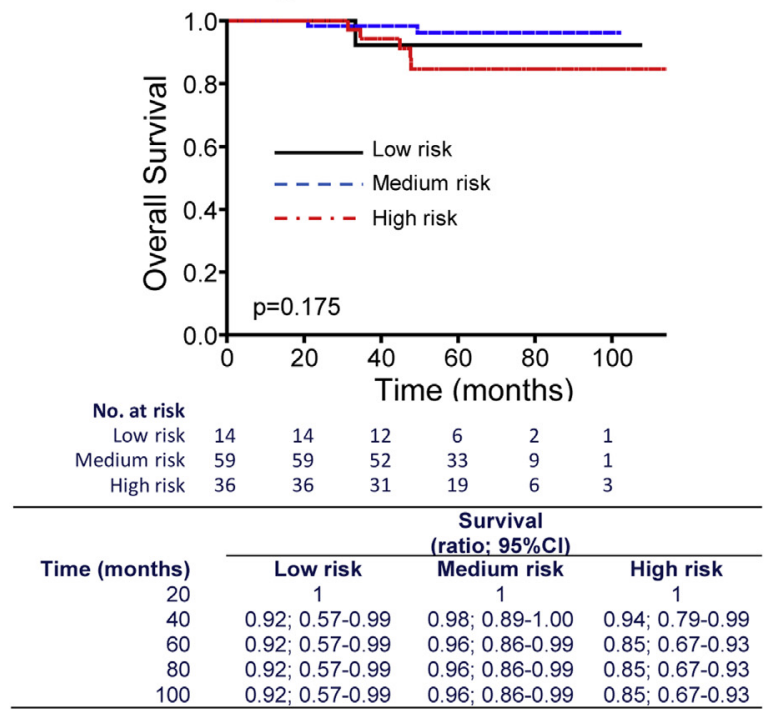

C

FIGURE E5. Evaluation of the capacity of the RNA metabolism signature to predict overall survival in lung adenocarcinoma patients of the GSE31210 dataset, divided by stage: (A) Stage I; (B) Stage II; (C) Stage IA; (D) Stage IB. The $P$ value of the log-rank test is shown in each graph. $C I$, Confidence interval.

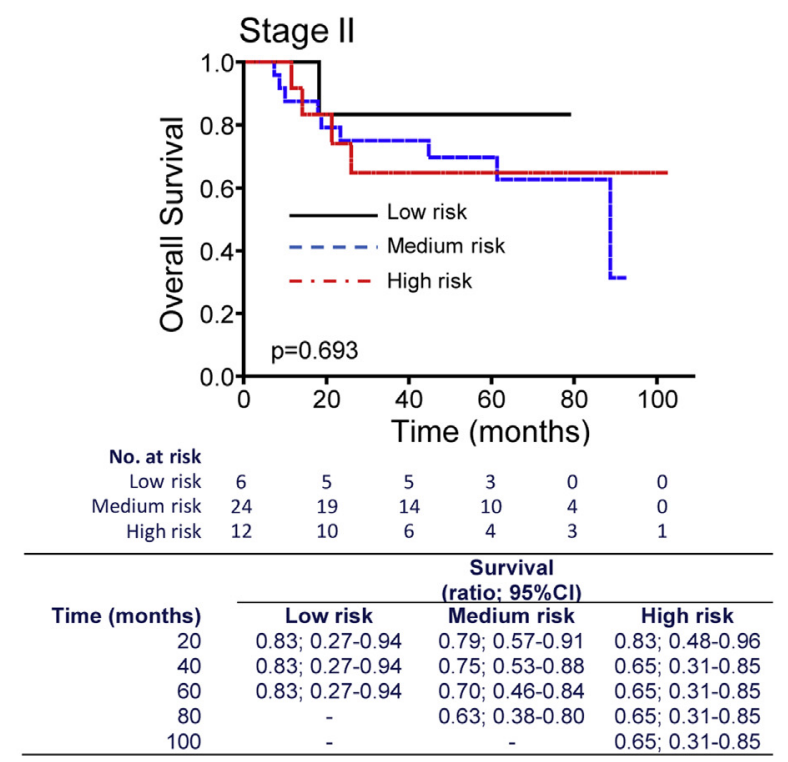

B

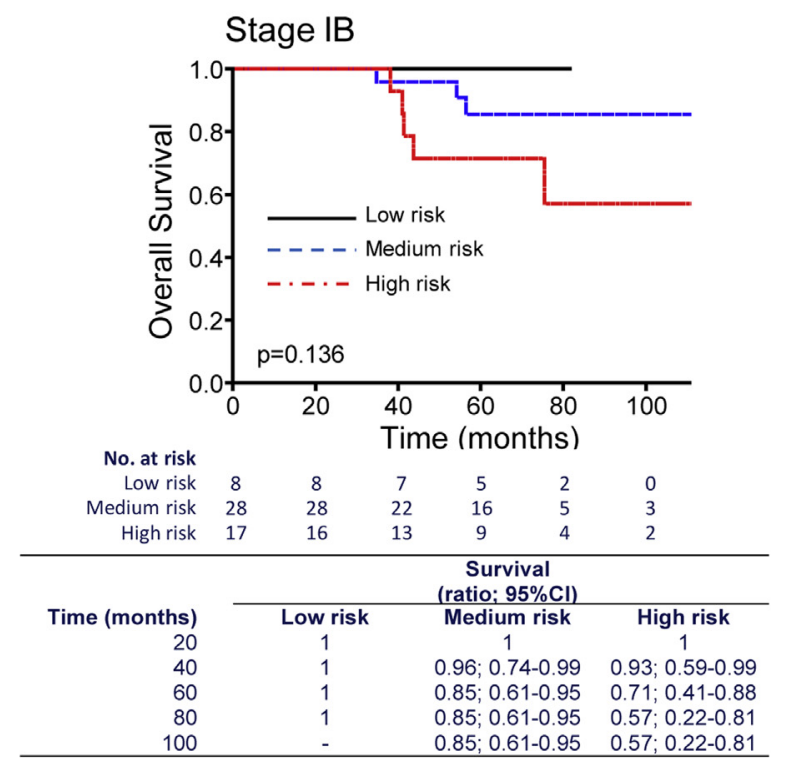

D 


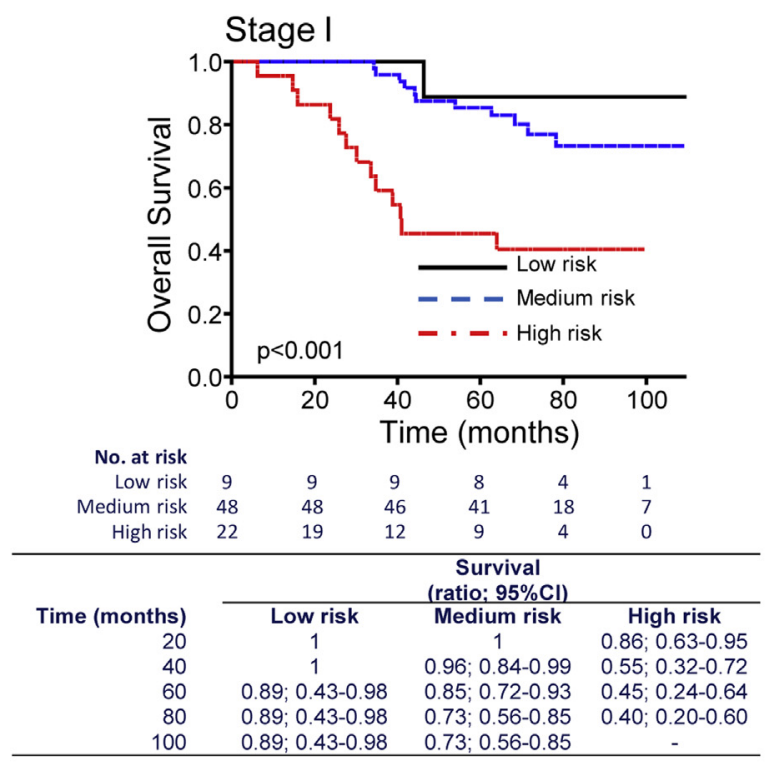

A

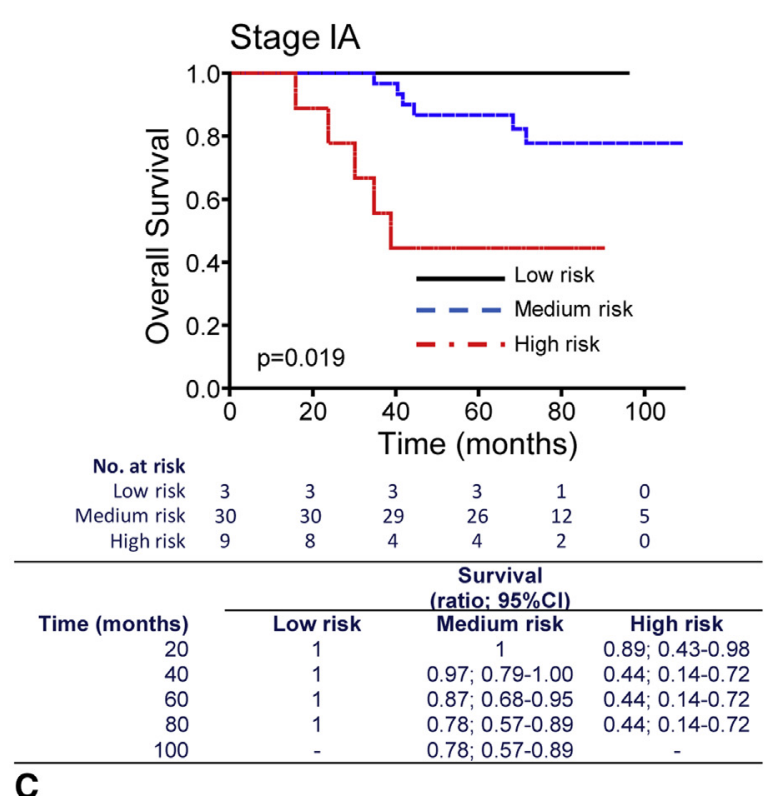

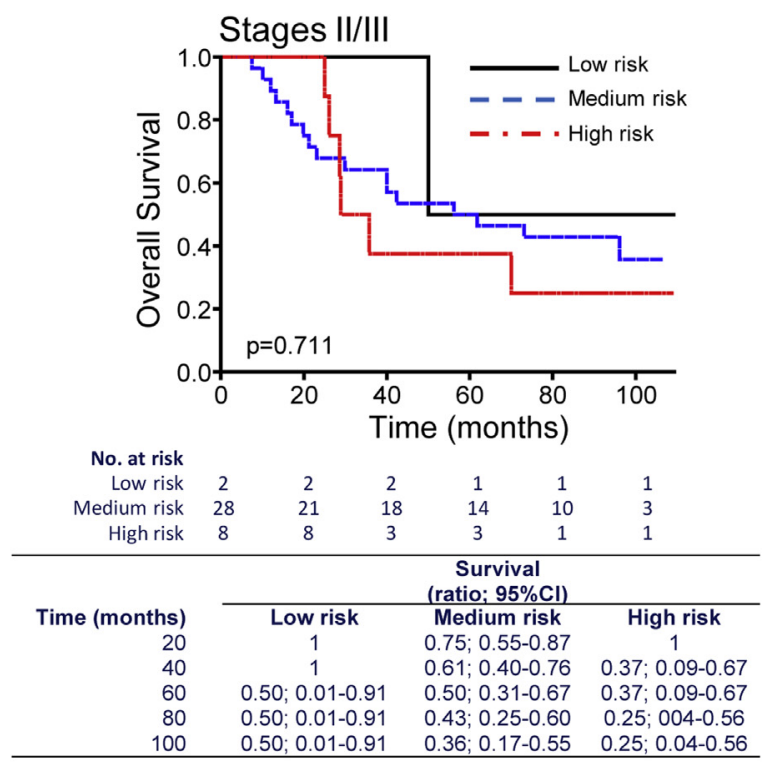

B

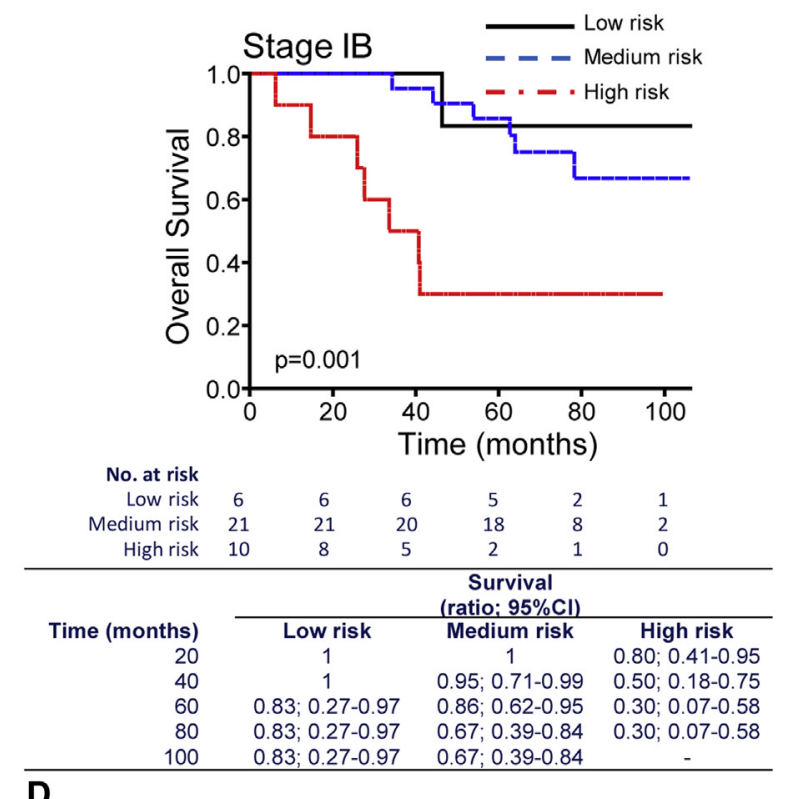

FIGURE E6. Evaluation of the capacity of the RNA metabolism signature to predict overall survival in lung adenocarcinoma patients of the GSE13213 dataset, divided by stage: (A) Stage I; (B) Stages II/III; (C) Stage IA; (D) Stage IB. The $P$ value of the log-rank test is shown in each graph. $C I$, Confidence interval. 

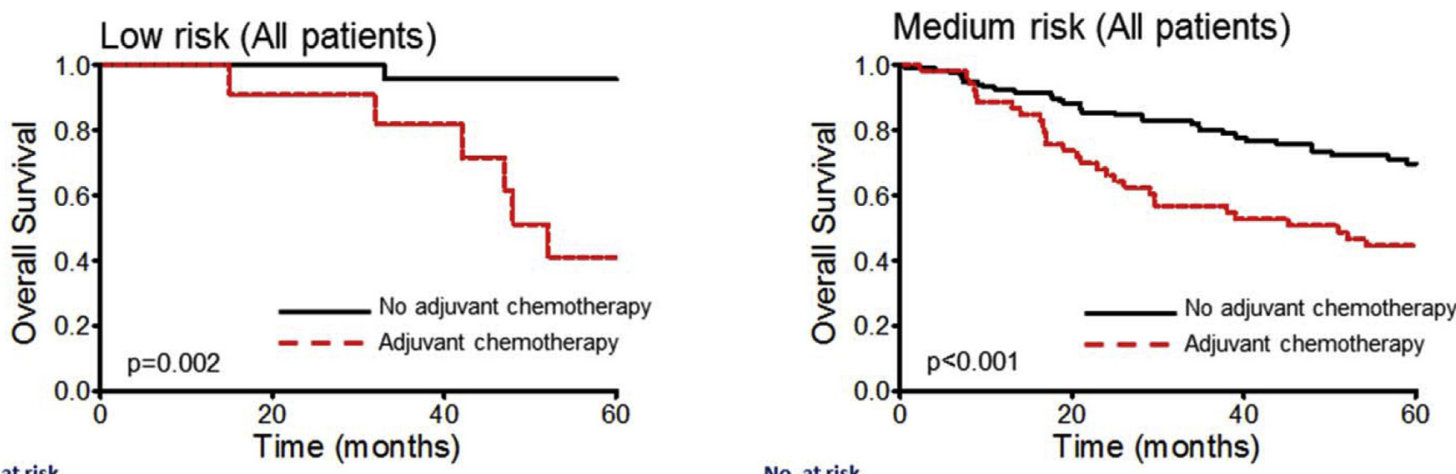

\begin{tabular}{|c|c|c|c|c|}
\hline \multirow{2}{*}{\multicolumn{2}{|c|}{ No. at risk }} & \multicolumn{3}{|l|}{ e (IIIO) } \\
\hline & & & & \\
\hline No adjuvant & 25 & 25 & 18 & 8 \\
\hline \multirow[t]{2}{*}{ Adjuvant } & 11 & 10 & 9 & 3 \\
\hline & & \multicolumn{3}{|c|}{ Survival (ratio; $95 \% \mathrm{Cl}$ ) } \\
\hline \multicolumn{2}{|c|}{ Time (months) } & No adjuvant therapy & \multicolumn{2}{|c|}{ Adjuvant therapy } \\
\hline \multicolumn{2}{|l|}{ ( } & 1 & \multicolumn{2}{|c|}{$0.91 ; 0.51-0.99$} \\
\hline & 40 & $0.96 ; 0.73-0.99$ & \multicolumn{2}{|c|}{$0.82 ; 0.45-0.95$} \\
\hline & 60 & $0.96 ; 0.73-0.99$ & \multicolumn{2}{|c|}{$0.41 ; 0.13-0.68$} \\
\hline
\end{tabular}

A

High risk (All patients)

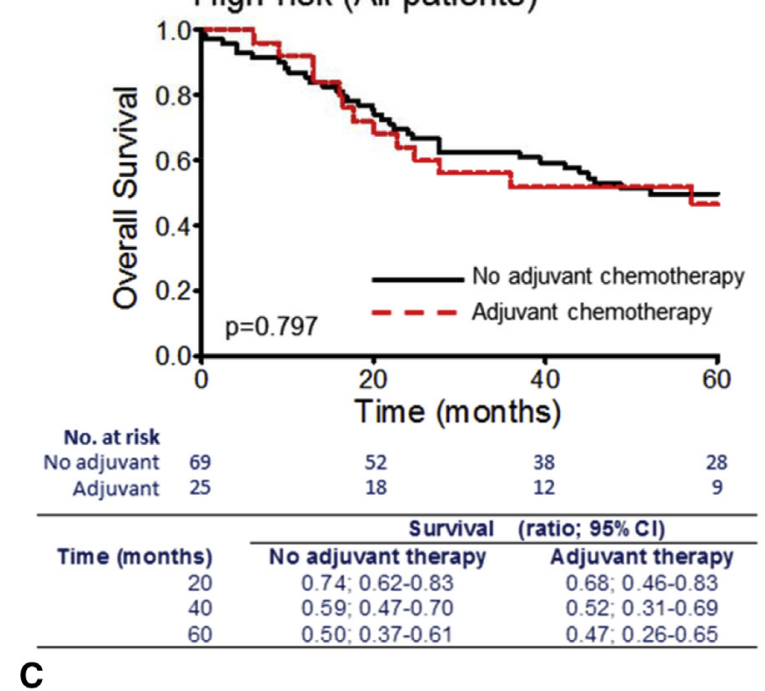

FIGURE E7. Association between the prognostic capacity of the RNA metabolism signature and the benefit of adjuvant chemotherapy in lung adenocarcinoma patients of the DCC dataset: (A) Low-risk group; (B) Medium-risk group; (C) High-risk group. Patients without any events were censored at 60 months. Patients were divided into risk groups based on the RNA metabolism score as indicated in the Methods section. The $P$ value of the log-rank test is shown in each graph. $C I$, Confidence interval. 
TABLE E1. Probesets in the various array platforms used to determine the expression of the 5 genes included in the RNA metabolism prognostic score

\begin{tabular}{llc}
\hline & \multicolumn{2}{c}{ Array platform } \\
\cline { 2 - 3 } Gene & Affymetrix & \multicolumn{1}{c}{ Agilent } \\
\hline ADAR2 & 203865_s_at & A_23_P211207 \\
MARS & 201475_x_at & A_24_P175909 \\
RAE1 & 211318 _s_at & A_23_P346206 \\
SNRPB & 208821_at & A_23_P154675 \\
SNRPE & 203316_S_at & A_23_P126291 \\
\hline
\end{tabular}

Affymetrix, Inc, and Agilent are based in Santa Clara, Calif.
TABLE E3. Kaplan-Meier estimates of survival in the 117 lung adenocarcinoma patients from the Aichi Cancer Center in Nagoya, Japan (GSE13213), separated by risk score

\begin{tabular}{lccc}
\hline & \multicolumn{3}{c}{ Overall survival $($ ratio [95\% CI]) } \\
\cline { 2 - 4 } Time (mo) & Low risk & Medium risk & High risk \\
\hline 20 & 1 & $0.92(0.83-0.96)$ & $0.87(0.69-0.95)$ \\
40 & 1 & $0.83(0.72-0.90)$ & $0.52(0.33-0.67)$ \\
60 & $0.90(0.47-0.99)$ & $0.72(0.61-0.81)$ & $0.42(0.25-0.58)$ \\
80 & $0.90(0.47-0.99)$ & $0.62(0.50-0.73)$ & $0.35(0.19-0.52)$ \\
100 & $0.90(0.47-0.99)$ & $0.58(0.43-0.70)$ & $0.35(0.19-0.52)$ \\
\hline
\end{tabular}

CI, Confidence interval.
TABLE E2. Kaplan-Meier estimates of survival in the 204 lung adenocarcinoma patients from the National Cancer Center Hospital in Tokyo, Japan (GSE31210), separated by risk score

\begin{tabular}{lccc}
\hline Time (mo) & Low risk & Medium risk & High risk \\
\hline $\begin{array}{l}\text { Relapse-free survival } \\
20\end{array}$ & 1 & $0.93(0.87-0.97)$ & $0.73(0.61-0.82)$ \\
40 & $0.96(0.76-0.99)$ & $0.85(0.76-0.90)$ & $0.61(0.48-0.72)$ \\
60 & $0.96(0.76-0.99)$ & $0.78(0.68-0.85)$ & $0.53(0.40-0.65)$ \\
80 & $0.96(0.76-0.99)$ & $0.74(0.61-0.83)$ & $0.53(0.40-0.65)$ \\
100 & $0.96(0.76-0.99)$ & $0.74(0.61-0.83)$ & $0.53(0.40-0.65)$ \\
Overall survival & & & \\
20 & 1 & $0.97(0.92-0.99)$ & $0.93(0.83-0.97)$ \\
40 & $0.96(0.74-0.99)$ & $0.95(0.89-0.98)$ & $0.83(0.72-0.90)$ \\
60 & $0.96(0.74-0.99)$ & $0.90(0.81-0.94)$ & $0.68(0.51-0.80)$ \\
80 & $0.96(0.74-0.99)$ & $0.88(0.79-0.93)$ & $0.68(0.51-0.80)$ \\
100 & $0.96(0.74-0.99)$ & $0.78(0.52-0.91)$ & $0.68(0.51-0.80)$ \\
\hline
\end{tabular}

Values are ratio $(95 \% \mathrm{CI})$.
TABLE E4. Kaplan-Meier estimates of overall survival in lung adenocarcinoma from patients in the low-, medium-, and high-risk groups, combined from the separate analyses performed in the DCC, GSE31210, and GSE13213 datasets

\begin{tabular}{lccc}
\hline & \multicolumn{3}{c}{ Overall survival (ratio [95\% CI] $)$} \\
\cline { 2 - 4 } Time (mo) & Low risk & Medium risk & High risk \\
\hline Stage I & & & \\
20 & 1 & $0.97(0.94-0.99)$ & $0.93(0.86-0.96)$ \\
40 & $0.98(0.86-1.00)$ & $0.92(0.88-0.95)$ & $0.78(0.70-0.85)$ \\
60 & $0.95(0.81-0.99)$ & $0.85(0.79-0.89)$ & $0.68(0.59-0.76)$ \\
80 & $0.95(0.81-0.99)$ & $0.95(0.81-0.99)$ & $0.62(0.49-0.72)$ \\
100 & $0.95(0.81-0.99)$ & $0.95(0.81-0.99)$ & $0.62(0.49-0.72)$ \\
Stage II/III & & & \\
20 & $0.93(0.61-0.99)$ & $0.75(0.64-0.83)$ & $0.67(0.49-0.79)$ \\
40 & $0.80(0.50-0.93)$ & $0.63(0.52-0.73)$ & $0.40(0.24-0.56)$ \\
60 & $0.72(0.41-0.89)$ & $0.54(0.42-0.64)$ & $0.33(0.18-0.49)$ \\
80 & $0.72(0.41-0.89)$ & $0.47(0.34-0.58)$ & $0.27(0.13-0.45)$ \\
100 & $0.72(0.41-0.89)$ & $0.35(0.19-0.52)$ & $0.27(0.13-0.45)$ \\
Stage IA & & & \\
20 & 1 & $0.99(0.94-1.00)$ & $0.99(0.90-1.00)$ \\
40 & $0.96(0.73-0.99)$ & $0.96(0.91-0.98)$ & $0.80(0.68-0.88)$ \\
60 & $0.96(0.73-0.99)$ & $0.91(0.84-0.95)$ & $0.75(0.62-0.84)$ \\
80 & $0.96(0.73-0.99)$ & $0.86(0.75-0.92)$ & $0.75(0.62-0.84)$ \\
100 & $0.96(0.73-0.99)$ & $0.86(0.75-0.92)$ & $0.75(0.62-0.84)$ \\
Stage IB & & & \\
20 & 1 & $0.96(0.90-0.98)$ & $0.84(0.70-0.91)$ \\
40 & 1 & $0.90(0.81-0.94)$ & $0.69(0.54-0.80)$ \\
60 & $0.93(0.61-0.99)$ & $0.78(0.67-0.85)$ & $0.55(0.40-0.68)$ \\
80 & $0.93(0.61-0.99)$ & $0.67(0.52-0.79)$ & $0.48(0.28-0.65)$ \\
100 & $0.93(0.61-0.99)$ & $0.67(0.52-0.79)$ & $0.48(0.28-0.65)$ \\
\hline$C I$, Confidence $)$ & & &
\end{tabular}

CI, Confidence interval. 
TABLE E5. Kaplan-Meier estimates of overall survival in stage-I adenocarcinoma patients from the DCC database, treated or untreated with adjuvant chemotherapy

\begin{tabular}{lcc}
\hline & \multicolumn{2}{c}{ Overall survival (ratio $[\mathbf{9 5} \% \mathbf{C I}])$} \\
\cline { 2 - 3 } Time (mo) & No adjuvant therapy & Adjuvant therapy \\
\hline Low risk & & \\
20 & 1 & $0.86(0.33-0.98)$ \\
40 & 1 & $0.86(0.33-0.98)$ \\
60 & & $0.51(0.12-0.81)$ \\
Medium risk & $0.93(0.85-0.97)$ & \\
20 & $0.86(0.76-0.92)$ & $0.91(0.68-0.98)$ \\
40 & $0.78(0.67-0.86)$ & $0.73(0.49-0.87)$ \\
60 & & \\
High risk & & $0.36-0.76)$ \\
20 & $0.88(0.75-0.94)$ & $0.80(0.41-0.95)$ \\
40 & $0.72(0.57-0.82)$ & $0.60(0.25-0.83)$ \\
60 & $0.63(0.48-0.75)$ & $0.48(0.16-0.74)$ \\
\hline
\end{tabular}

CI, Confidence interval.
TABLE E7. Demographics and clinical characteristics of the 204 lung adenocarcinoma patients from the National Cancer Center Hospital in Tokyo, Japan (GSE31210)

\begin{tabular}{lr}
\hline Age $(\mathrm{y})$, mean $\pm \mathrm{SD}$ & $59.6 \pm 7.50$ \\
Gender & \\
Female & $109(53)$ \\
Male & $95(47)$ \\
Smoking status & \\
Never-smoker & $105(51)$ \\
Ever-smoker & $99(49)$ \\
Stage & \\
I & $162(79)$ \\
II & $42(21)$ \\
\hline
\end{tabular}

Values are $\mathrm{n}(\%)$, unless otherwise indicated. $S D$, Standard deviation.
TABLE E6. Kaplan-Meier estimates of overall survival in stage-II/III adenocarcinoma patients from the DCC database, treated or untreated with adjuvant chemotherapy

\begin{tabular}{lcc}
\hline & \multicolumn{2}{c}{ Overall survival (ratio [95\% CI] $)$} \\
\cline { 2 - 3 } Time (mo) & No adjuvant therapy & Adjuvant therapy \\
\hline Low risk & 1 & 1 \\
20 & $0.71(0.26-0.92)$ & $0.50(0.01-0.91)$ \\
40 & $0.71(0.26-0.92)$ & - \\
60 & & $0.63(0.45-0.76)$ \\
Medium risk & $0.74(0.55-0.86)$ & $0.43(0.26-0.58)$ \\
20 & $0.60(0.40-0.75)$ & $0.36(0.21-0.52)$ \\
40 & $0.42(0.22-0.62)$ & \\
60 & & $0.58(0.27-0.80)$ \\
High risk & $0.31(0.11-0.54)$ & $0.42(0.15-0.67)$ \\
20 & $0.19(0.05-0.40)$ & $0.42(0.15-0.67)$ \\
40 & $0.09(0.01-0.32)$ & \\
60 &
\end{tabular}

CI, Confidence interval.
TABLE E8. Demographics and clinical characteristics of the 117 lung adenocarcinoma patients from the Aichi Cancer Center in Nagoya, Japan (GSE13213)

\begin{tabular}{lc}
\hline Age $(\mathrm{y})$, mean $\pm \mathrm{SD}$ & $60.7 \pm 10.17$ \\
Gender & \\
$\quad$ Female & $57(49)$ \\
$\quad$ Male & $60(51)$ \\
Smoking status & \\
$\quad$ Never-smoker & $56(48)$ \\
$\quad$ Ever-smoker & $61(52)$ \\
Stage & \\
$\quad$ I & $79(68)$ \\
II & $13(11)$ \\
III & $25(21)$ \\
\hline Values are $\mathrm{n}(\%)$, unless otherwise indicated. SD, Standard deviation.
\end{tabular}


TABLE E9. Univariate Cox regression analysis for relapse-free survival in the 204 lung adenocarcinoma patients from the National Cancer Center Hospital in Tokyo, Japan (GSE31210)

\begin{tabular}{|c|c|c|c|}
\hline Factor & $\mathbf{n}$ & Hazard ratio $(95 \%$ CI $)$ & $P$ value \\
\hline \multicolumn{4}{|l|}{ Age $(y)$} \\
\hline$\leq 60$ & 99 & 1 & .106 \\
\hline$>60$ & 105 & $1.57(0.91-2.71)$ & \\
\hline \multicolumn{4}{|l|}{ Gender } \\
\hline Female & 109 & 1 & .220 \\
\hline Male & 95 & $1.40(0.82-2.38)$ & \\
\hline \multicolumn{4}{|l|}{ Smoking status } \\
\hline Never-smoker & 105 & 1 & .190 \\
\hline Ever-smoker & 99 & $1.43(0.84-2.44)$ & \\
\hline \multicolumn{4}{|l|}{ Stage } \\
\hline I & 162 & 1 & $<.001$ \\
\hline II & 42 & $3.44(1.98-6.00)$ & \\
\hline \multicolumn{4}{|l|}{ EGFR } \\
\hline Wild-type & 88 & 1 & .041 \\
\hline Mutated & 116 & $0.57(0.33-0.98)$ & \\
\hline \multicolumn{4}{|l|}{ KRAS } \\
\hline Wild-type & 185 & 1 & .744 \\
\hline Mutated & 19 & $1.15(0.49-2.69)$ & \\
\hline \multicolumn{4}{|l|}{ ALK } \\
\hline Wild-type & 197 & 1 & .581 \\
\hline Fused & 7 & $0.57(0.79-4.14)$ & \\
\hline \multicolumn{4}{|l|}{ c-Myc } \\
\hline Low & 187 & 1 & .611 \\
\hline High & 16 & $1.26(0.52-3.06)$ & \\
\hline Not determined & 1 & & \\
\hline \multicolumn{4}{|l|}{ Prognostic score } \\
\hline 0 & 26 & 1 & $<.001$ \\
\hline $1-3$ & 110 & $5.96(0.80-44.13)$ & \\
\hline 4,5 & 68 & $15.63(2.13-114.69)$ & \\
\hline
\end{tabular}

TABLE E10. Univariate Cox regression analysis for overall survival in the 204 lung adenocarcinoma patients from the National Cancer Center Hospital in Tokyo, Japan (GSE31210)

\begin{tabular}{|c|c|c|c|}
\hline Factor & $\mathbf{n}$ & Hazard ratio $(95 \%$ CI $)$ & $P$ value \\
\hline \multicolumn{4}{|l|}{ Age (y) } \\
\hline$\leq 60$ & 99 & 1 & .515 \\
\hline$>60$ & 105 & $1.27(0.62-2.62)$ & \\
\hline \multicolumn{4}{|l|}{ Gender } \\
\hline Female & 109 & 1 & .157 \\
\hline Male & 95 & $1.69(0.82-3.48)$ & \\
\hline \multicolumn{4}{|l|}{ Smoking status } \\
\hline Never-smoker & 105 & 1 & .084 \\
\hline Ever-smoker & 99 & $1.91(0.92-3.97)$ & \\
\hline \multicolumn{4}{|l|}{ Stage } \\
\hline I & 162 & 1 & $<.001$ \\
\hline II & 42 & $4.30(2.09-8.83)$ & \\
\hline \multicolumn{4}{|l|}{ EGFR } \\
\hline Wild-type & 88 & 1 & .038 \\
\hline Mutated & 116 & $0.46(0.22-0.96)$ & \\
\hline \multicolumn{4}{|l|}{ KRAS } \\
\hline Wild-type & 185 & 1 & .989 \\
\hline Mutated & 19 & $0.99(0.30-3.28)$ & \\
\hline \multicolumn{4}{|l|}{ ALK } \\
\hline Wild-type & 197 & 1 & .956 \\
\hline Fused & 7 & $1.06(0.14-7.78)$ & \\
\hline \multicolumn{4}{|l|}{ c-Myc } \\
\hline Low & 187 & 1 & .765 \\
\hline High & 16 & $0.81(0.21-3.17)$ & \\
\hline Not determined & 1 & & \\
\hline \multicolumn{4}{|l|}{ Prognostic score } \\
\hline 0 & 26 & 1 & .011 \\
\hline $1-3$ & 110 & $2.85(0.37-21.89)$ & \\
\hline 4,5 & 68 & $7.49(1.00-56.33)$ & \\
\hline
\end{tabular}


TABLE E11. Univariate Cox regression analysis for overall survival in the 117 lung adenocarcinoma patients from the Aichi Cancer Center in Nagoya, Japan (GSE13213)

\begin{tabular}{|c|c|c|c|}
\hline Factor & $\mathbf{n}$ & Hazard ratio $(95 \%$ CI $)$ & $P$ value \\
\hline \multicolumn{4}{|l|}{ Age $(y)$} \\
\hline$\leq 60$ & 52 & 1 & .890 \\
\hline$>60$ & 65 & $1.04(0.59-1.83)$ & \\
\hline \multicolumn{4}{|l|}{ Gender } \\
\hline Female & 57 & 1 & .286 \\
\hline Male & 60 & $1.36(0.77-2.39)$ & \\
\hline \multicolumn{4}{|l|}{ Smoking status } \\
\hline Never-smoker & 56 & 1 & .284 \\
\hline Ever-smoker & 61 & $1.36(0.77-2.39)$ & \\
\hline \multicolumn{4}{|l|}{ Stage } \\
\hline I & 79 & 1 & .001 \\
\hline II/III & 38 & $2.53(1.44-4.45)$ & \\
\hline \multicolumn{4}{|l|}{ EGFR } \\
\hline Wild-type & 72 & 1 & .945 \\
\hline Mutated & 45 & $1.02(0.57-1.82)$ & \\
\hline \multicolumn{4}{|l|}{ KRAS } \\
\hline Wild-type & 102 & 1 & .272 \\
\hline Mutated & 15 & $1.53(0.72-3.27)$ & \\
\hline \multicolumn{4}{|l|}{ TP53 } \\
\hline Wild-type & 78 & 1 & .322 \\
\hline Mutated & 38 & $1.33(0.75-2.38)$ & \\
\hline Not determined & 1 & & \\
\hline \multicolumn{4}{|l|}{ Prognostic score } \\
\hline 0 & 10 & 1 & $<.001$ \\
\hline $1-3$ & 76 & $4.21(0.57-30.92)$ & \\
\hline 4,5 & 31 & $10.16(1.36-75.83)$ & \\
\hline
\end{tabular}

Boldface indicates statistical significance. $C I$, Confidence interval.
TABLE E12. Demographics and clinical characteristics of the 302 lung adenocarcinoma patients from the Director's Challenge Consortium for the Molecular Classification of Lung Adenocarcinoma dataset

\begin{tabular}{lcc}
\hline & \multicolumn{2}{c}{ Chemotherapy } \\
\cline { 2 - 3 } Characteristic & No & Yes \\
\hline Age (y), mean \pm SD & $64.6 \pm 10.3$ & $61.6 \pm 9.8$ \\
Gender & & \\
$\quad$ Female & $116(54)$ & $49(55)$ \\
$\quad$ Male & $97(46)$ & $40(45)$ \\
Smoking status & & \\
$\quad$ Never-smoker & $27(13)$ & $14(16)$ \\
Ever-smoker & $179(87)$ & $73(84)$ \\
NA (n) & 7 & 2 \\
Stage & $157(74)$ & $39(44)$ \\
I & $35(17)$ & $27(31)$ \\
II & $19(9)$ & $22(25)$ \\
III & 2 & 1 \\
$\quad$ NA (n) & & \\
Values are n (\%), unless otherwise indicated. NA, Not available; $S D$, standard \\
deviation.
\end{tabular}

